\title{
PKR activation and elF2 $\alpha$ phosphorylation mediate human globin mRNA splicing at spliceosome assembly
}

\author{
Lena Ilan ${ }^{1, *}$, Farhat Osman ${ }^{1, *}$, Lise Sarah Namer ${ }^{1, *}$, Einav Eliahu ${ }^{1}$, Smadar Cohen-Chalamish ${ }^{1}$, Yitzhak Ben-Asouli ${ }^{1}$, \\ Yona Banai ${ }^{1}$, Raymond Kaempfer ${ }^{1}$ \\ ${ }^{I}$ Department of Biochemistry and Molecular Biology, Institute of Medical Research Israel-Canada, The Hebrew University-Hadas- \\ sah Medical School, Jerusalem, Israel
}

Short elements in mammalian mRNA can control gene expression by activating the RNA-dependent protein kinase PKR that attenuates translation by phosphorylating cytoplasmic eukaryotic initiation factor $2 \alpha$ (eIF2 $\alpha$ ). We demonstrate a novel, positive role for PKR activation and eIF2 $\alpha$ phosphorylation in human globin mRNA splicing. PKR localizes in splicing complexes and associates with splicing factor SC35. Splicing and early-stage spliceosome assembly on $\beta$-globin pre-mRNA depend strictly on activation of PKR by a codon-containing RNA fragment within exon 1 and on phosphorylation of nuclear eIF $2 \alpha$ on Serine 51. Nonphosphorylatable mutant eIF2 $\alpha$ S51 A blocked $\beta$-globin mRNA splicing in cells and nuclear extract. Mutations of the $\beta$-globin RNA activator abrogated PKR activation and profoundly affected mRNA splicing efficiency. PKR depletion abrogated splicing and spliceosome assembly; recombinant PKR effectively restored splicing. Excision of the first intron of $\beta$-globin induces strand displacement within the RNA activator of PKR by a sequence from exon 2, a structural rearrangement that silences the ability of spliced $\beta$-globin mRNA to activate PKR. Thus, the ability to activate PKR is transient, serving solely to enable splicing. $\alpha$-Globin pre-mRNA splicing is controlled likewise but positions of PKR activator and silencer are reversed, demonstrating evolutionary flexibility in how PKR activation regulates globin mRNA splicing through elF2 $\alpha$ phosphorylation. Keywords: globin mRNA splicing; eIF2 $\alpha$ phosphorylation; PKR; RNA activator of PKR; spliceosome assembly Cell Research (2017) 27:688-704. doi:10.1038/cr.2017.39; published online 4 April 2017

\section{Introduction}

The RNA-dependent protein kinase R (PKR) is an intracellular sensor of stress that plays a central role in antiviral defense and innate immunity [1]. Double-stranded RNA generated during viral replication activates PKR, which inhibits protein synthesis by phosphorylating the $\alpha$-subunit of eukaryotic translation initiation factor 2 (eIF $2 \alpha$ ) on Ser51; phosphorylation of eIF $2 \alpha$ blocks GTP/ GDP exchange needed for recycling of eIF2 between rounds of translation initiation [2]. eIF $2 \alpha$ phosphorylation is critical for mounting the integrated cellular stress response [3-5]. Activation of PKR in the cytoplasm leads

*These three authors contributed equally to this work.

Correspondence: Raymond Kaempfer

Tel: +972 26758389

E-mail:kaempfer@hebrew.edu

Received 20 July 2016; revised 20 November 2016; accepted 30 December 2016; published online 4 April 2017 to eIF $2 \alpha$ phosphorylation that results in a block of translation of mRNAs such as globin mRNA $[6,7]$.

Effective engagement of the tandem RNA-binding domains of PKR needed for trans-autophosphorylation of the PKR dimer and the subsequent kinase activation [8, 9] requires double-helical RNA of minimally 16-18 base pairs (bp) [10] and optimally 40-80 bp [11]. However, short elements within mammalian mRNA can regulate specific gene expression by activating PKR, as shown for the human genes encoding inflammatory cytokines, such as tumor necrosis factor- $\alpha$ (TNF- $\alpha)$ [12] and interferon- $\gamma$ (IFN- $\gamma$ ) [13]. IFN- $\gamma$ mRNA activates PKR through a 5 '-proximal pseudoknot, resulting in eIF $2 \alpha$ phosphorylation and attenuation of its own translation through a negative feedback loop $[13,14]$. Efficient splicing of $T N F-\alpha$ pre-mRNA is dependent on a short element in the $3^{\prime}$-untranslated region (3'-UTR) that potently activates PKR [12]. This cis-acting RNA element, conserved from teleost fish to humans, folds into a pseudoknot that is critical for PKR activation and mRNA splicing. Splicing enabled 
by the $T N F-\alpha$ RNA activator of PKR depends strictly on phosphorylation of eIF $2 \alpha$ on Ser51 that yet does not repress translation. Indeed, eIF2 $\alpha$ phosphorylation is not only necessary but also sufficient to achieve efficient splicing of $T N F-\alpha$ mRNA (manuscript in submission). eIF $2 \alpha$ phosphorylation positively controls $T N F-\alpha$ mRNA splicing in primary human immune cells, showing its physiological relevance, but the mechanism behind this need remains to be resolved.

Hemoglobin production depends on a massive expression of globin mRNA [15] that demands highly efficient splicing of precursor transcripts. We report here that splicing of $\alpha$ - and $\beta$-globin pre-mRNAs depends strictly on the activation of PKR by intragenic RNA activators that overlap with translated codons. Splicing of $\beta$-globin mRNA is abrogated by PKR depletion, which can be restored by adding back recombinant PKR. The RNA activator of PKR in $\beta$-globin pre-mRNA resides in the first exon; mutations of a short helix within this activator profoundly affected both PKR activation and mRNA splicing. Efficient globin mRNA splicing requires phosphorylation of eIF $2 \alpha$. PKR activation and eIF $2 \alpha$ phosphorylation mediate splicing at an early step in $\beta$-globin spliceosome assembly.

The activator of PKR in $\beta$-globin pre-mRNA is generated from 5 '-UTR sequence and the start of the open reading frame (ORF), as in the case of $I F N-\gamma$ mRNA [13, 14]. However, we show that excision of the first intron of $\beta$-globin induces strand displacement within exon 1 by a sequence from exon 2 that affects base pairing in the short helix critical for PKR activation, resulting in silencing of the PKR activator within the spliced mRNA. In this manner, the ability to activate PKR is transient, solely to enable splicing.

Our results link a mechanism that controls mRNA translation in the cytoplasm, i.e., phosphorylation of the eIF $2 \alpha$ chain upon RNA-mediated activation of PKR, to a critical step in globin mRNA splicing in the nucleus. The finding that splicing of the globin mRNAs is mediated by intragenic RNA activators of PKR shows that this stress response kinase is used more widely beyond the immune system to effect post-transcriptional upregulation of specific genes.

\section{Results}

\section{PKR inhibitors block splicing of $\beta$-globin mRNA}

We followed excision of human $\beta$-globin introns 1 (Figure 1A) and 2 (Figure 1B) in transfected cells by means of antisense RNA probes. Addition of 2-aminopurine (2-AP), an inhibitor of eIF $2 \alpha$ kinases [16] that blocks splicing of TNF- $\alpha$ mRNA [12], induced accumulation of unspliced $\beta$-globin pre-mRNA at the expense of spliced mRNA, leading to an increase in pre-mRNA/mRNA ratio (Figure 1A-1B). When we expressed a $\beta$-globin gene from which intron 2 had been deleted, intron 1 failed to be excised and only unspliced pre-mRNA was recovered (Figure 1C), in agreement with earlier observations [17]. This result implies that intron 1 must be excised before intron 2 deletion, rendering removal of intron 1 the critical first step in $\beta$-globin mRNA splicing. Once intron 1 has been excised, splicing is completed efficiently (Figure 1B, lanes without 2-AP).

We next created constructs containing $\beta$-globin exons 1 and 2 wherein the $\beta$-globin coding sequence is fused in-frame to green fluorescent protein (GFP) ORF (Figure 1D). When splicing is blocked, the construct containing intron 1 would generate an RNA product having a stop codon in the intron, precluding expression of GFP. Cells transfected with the intronless construct expressed GFP regardless of the addition of 2-AP or co-expression of PKR $\Delta 6$, a dominant-negative mutant of human PKR (Figure 1E). By contrast, these treatments abolished GFP expression when intron 1 was present (Figure 1E). By forming heterodimers with wild-type (wt) PKR, kinase-dead PKR $\Delta 6$ blocks its activation [18]. Therefore, 2 -AP and PKR $\Delta 6$ blocked excision of the $\beta$-globin intron in globin-GFP pre-mRNA. Unlike the case of $\beta$-globin pre-mRNA (Figure 1C), globin-GFP pre-mRNA splicing was not impeded by lack of the second intron; apparently, due to the lack of exon 3, the downstream sequence does not interfere with upstream splicing. Moreover, in a HeLa cell nuclear extract, splicing of a $\beta$-globin pre-mRNA template consisting of exon 1, intron 1 and exon 2 but lacking downstream sequence [19] was inhibited completely by 2-AP (Figure 1F). The effect of 2-AP resembled that of okadaic acid, a known splicing inhibitor [20] (Figure 1G). These results suggest that splicing of $\beta$-globin pre-mRNA requires activation of PKR.

To examine the hypothesis that $\beta$-globin pre-mRNA functions as an activator of PKR, we studied its ability to activate recombinant human holo-PKR expressed in an RNA-activatable form (rPKR) [14]. We used adenovirus $M I N X$ pre-mRNA, an efficient template for in vitro splicing [21], and the 5'-terminal fragment of human IFN- $\gamma$ mRNA, which is a potent activator of PKR $[13,14]$ as negative and positive controls, respectively. In contrast to MINX pre-mRNA, the $\beta$-globin pre-mRNA template strongly activated PKR, manifested by autophosphorylation of the kinase (Figure 1H).

Splicing of $\beta$-globin mRNA is dependent on PKR activation

Similar to an antibody $(\mathrm{Ab})$ against splicing factor $\mathrm{SC} 35$, an Ab against total PKR blocked splicing of $\beta$-glo- 


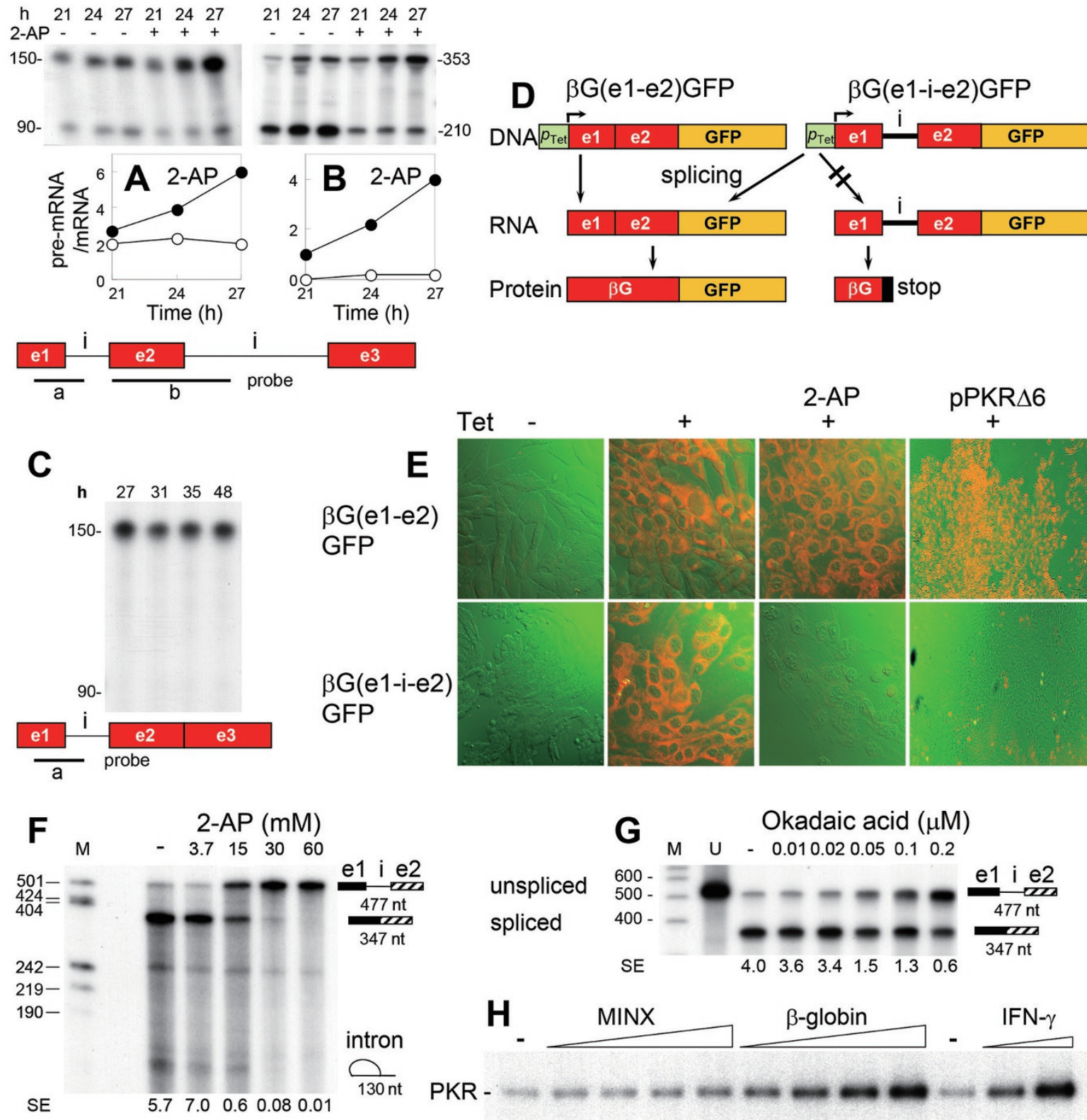

Figure 1 Splicing of $\beta$-globin mRNA is blocked by PKR inhibitors. (A, B) Expression of unspliced pre-mRNA (reflected by the 150-nt (A) or 353-nt (B) band) and spliced mRNA of $\beta$-globin (reflected by the 90-nt (A) or 210-nt (B) band) in HEK293 cells transfected with the human $\beta$-globin gene, assayed by RNase protection analysis using RNA probes a (A) or b (B) (e, exon; $\mathrm{i}$, intron). Where indicated, $15 \mathrm{mM}$ 2-AP was added $18 \mathrm{~h}$ after the transfection. Ratio of pre-mRNA/mRNA in the absence (०) or presence of 2-AP $(\bullet)$ is plotted. (C) Expression of $\beta$-globin RNA in HEK293 cells transfected with the $\beta$-globin gene lacking intron 2, assayed with probe a. (D, E) Inhibition of $\beta$-globin intron 1 excision by 2-AP and a dominant-negative mutant of PKR. BHK-21 cells were stably transfected with fusion constructs $p \beta G(e 1-e 2) G F P$ and $p \beta G(e 1-i-e 2) G F P$ lacking and containing intron 1, respectively, under the tetracycline-activatable promoter (pTet) (D). Expression of $\beta$-globin/GFP protein was induced by the treatment with $12.5 \mathrm{pg} / \mathrm{ml}$ Tet for $6 \mathrm{~h}$. Where indicated, $20 \mathrm{mM}$ 2-AP was added $14 \mathrm{~h}$ before induction, or cells were transfected with $2 \mathrm{~g}$ pPKR $\triangle 6$ DNA [9] $17 \mathrm{~h}$ before induction. Confocal microscopy of fluorescence is shown (GFP, orange); $\mathrm{PKR} \Delta 6$ panels are at lower magnification $(\mathbf{E}) .(\mathbf{F}, \mathbf{G})$ In vitro splicing of $\beta$-globin pre-mRNA is blocked by 2 -AP and okadaic acid. Splicing of capped, ${ }^{32} \mathrm{P}$-labeled 477-nt $\beta$-globin precursor transcript in HeLa cell nuclear extract was analyzed as described in Materials and Methods section, in the presence of 2-AP (F) or okadaic acid (G). Position of intron lariat is indicated in $\mathbf{F}$. M, marker DNA; U, input unspliced RNA. Splicing efficiency (SE), defined as a ratio of spliced/unspliced RNA, is provided under each lane. (H) Activation of PKR by $\beta$-globin pre-mRNA. rPKR was incubated with the 477-nt $\beta$-globin pre-mRNA template or 226nt MINX pre-mRNA $(0.75,2.25,3.75$ and $7.5 \mathrm{nM})$ or with 203-nt 5'-terminal fragment of human IFN- $\gamma$ mRNA (0.75 and 2.25 $\mathrm{nM})$ in the presence of $\left[\gamma_{-}{ }^{32} \mathrm{P}\right] \mathrm{ATP}$ as described in Materials and Methods section. Autoradiogram shows phosphorylated PKR. 
bin pre-mRNA template in vitro (Figure 2A). Anti-PKR Abs against the catalytic domain (Figure 2B) or the RNA-binding domain of the kinase (Figure 2C) blocked splicing of $\beta$-globin pre-mRNA template, as did a monoclonal antibody $(\mathrm{mAb})$ specific for phosphorylated PKR (Figure 2D). Thus, $\beta$-globin mRNA splicing not only requires PKR but the kinase must be phosphorylated and hence activated. Indeed, splicing was also abrogated by PKR $\Delta 6$ (Figure 2E). Whereas anti-phospho-PKR mAb inhibited splicing of $\beta$-globin pre-mRNA template, it did not affect splicing of MINX pre-mRNA, showing specificity (Figure 2F). In the presence of anti-phospho-PKR $\mathrm{mAb}$, unspliced $\beta$-globin pre-mRNA accumulated yet there was no accumulation of unspliced MINX RNA (Figure 2F).

PKR is found in splicing complexes and is needed for spliceosome formation

To investigate whether PKR associates with the $\beta$-globin pre-mRNA splicing complex, we performed the in

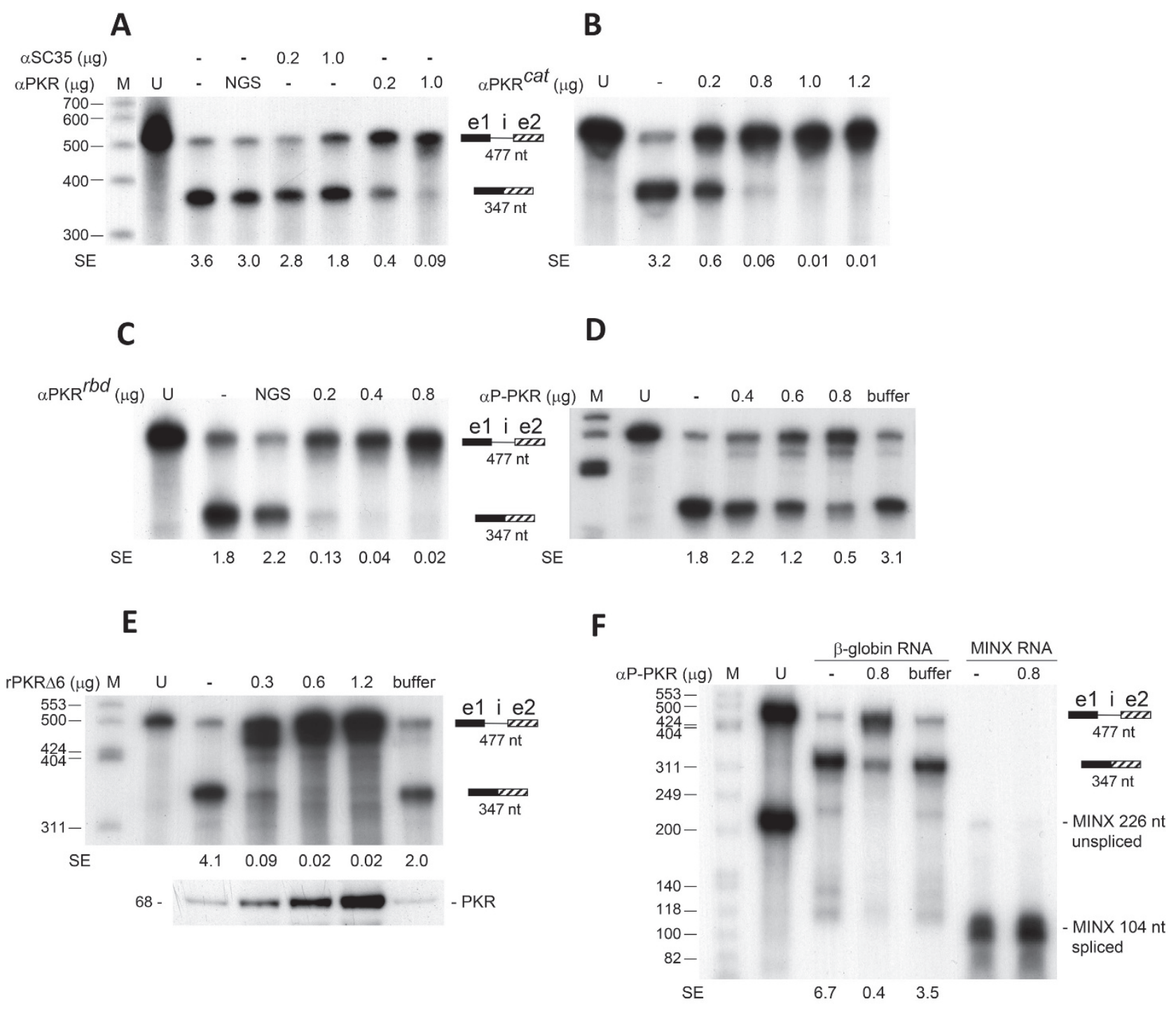

Figure 2 Splicing of $\beta$-globin mRNA depends on PKR activation. (A-F) Splicing of $\beta$-globin pre-mRNA template is blocked by anti-PKR Abs and the dominant-negative mutant of PKR. In vitro splicing was performed as in Figure $1 \mathrm{~F}$. Where indicated, normal goat serum (NGS, $1 \mu \mathrm{g})(\mathbf{A}, \mathbf{C})$, polyclonal Ab against SC35 ( $\alpha$ SC35), holo-PKR $(\alpha \mathrm{PKR})(\mathbf{A})$, the catalytic domain of PKR $\left(\alpha \mathrm{PKR}^{\mathrm{cat}}\right)(\mathrm{B})$ or the RNA-binding domain of PKR $\left(\alpha \mathrm{PKR}^{\mathrm{rbd}}\right)(\mathbf{C})$, anti-phospho-PKR mAb $(\alpha \mathrm{P}-\mathrm{PKR})$ specific for phospho-Thr446 (D, F), or rPKR 46 (E) was added in the amounts shown. Western blot of PKR in reaction mixtures is shown at bottom in E. Effect of $\alpha$ P-PKR on splicing of the $\beta$-globin pre-mRNA template and MINX pre-mRNA is compared in F. Buffer, corresponding protein storage buffer. SE, splicing efficiency. 
vitro splicing reaction for $30 \mathrm{~min}$ and then immunoprecipitated holo-PKR or SC35, the latter of which is present in active splicing complexes [22]. Abs against SC35 precipitated PKR from HeLa cell nuclear extract and vice versa, Abs against PKR precipitated SC35 (Figure 3A). Confocal microscopy of intact cells confirmed that PKR is present in both cytoplasm and nucleus, and it colocalizes with SC35 to the nuclear speckles (Supplementary information, Figure S1A), sites of mRNA splicing [23], supporting the inhibition of splicing by Abs against PKR and SC35 (Figure 2A) and the co-immunoprecipitation of these two proteins (Figure 3A). To investigate wheth- er PKR is essential for splicing complex formation, we studied kinetics of ribonucleoprotein formation during in vitro splicing using labeled $\beta$-globin pre-mRNA template. Appearance of the spliceosomal complex A preceded that of complexes B and C (Figure 3B). Preincubation of HeLa cell nuclear extract with Abs against the catalytic or RNA-binding domain of PKR sufficed to abrogate formation of complex A yet did not affect formation of early complex $\mathrm{H}$, which is not committed to splicing [24] (Figure 3B). We conclude that PKR associates with splicing complexes and is needed early in spliceosome formation.
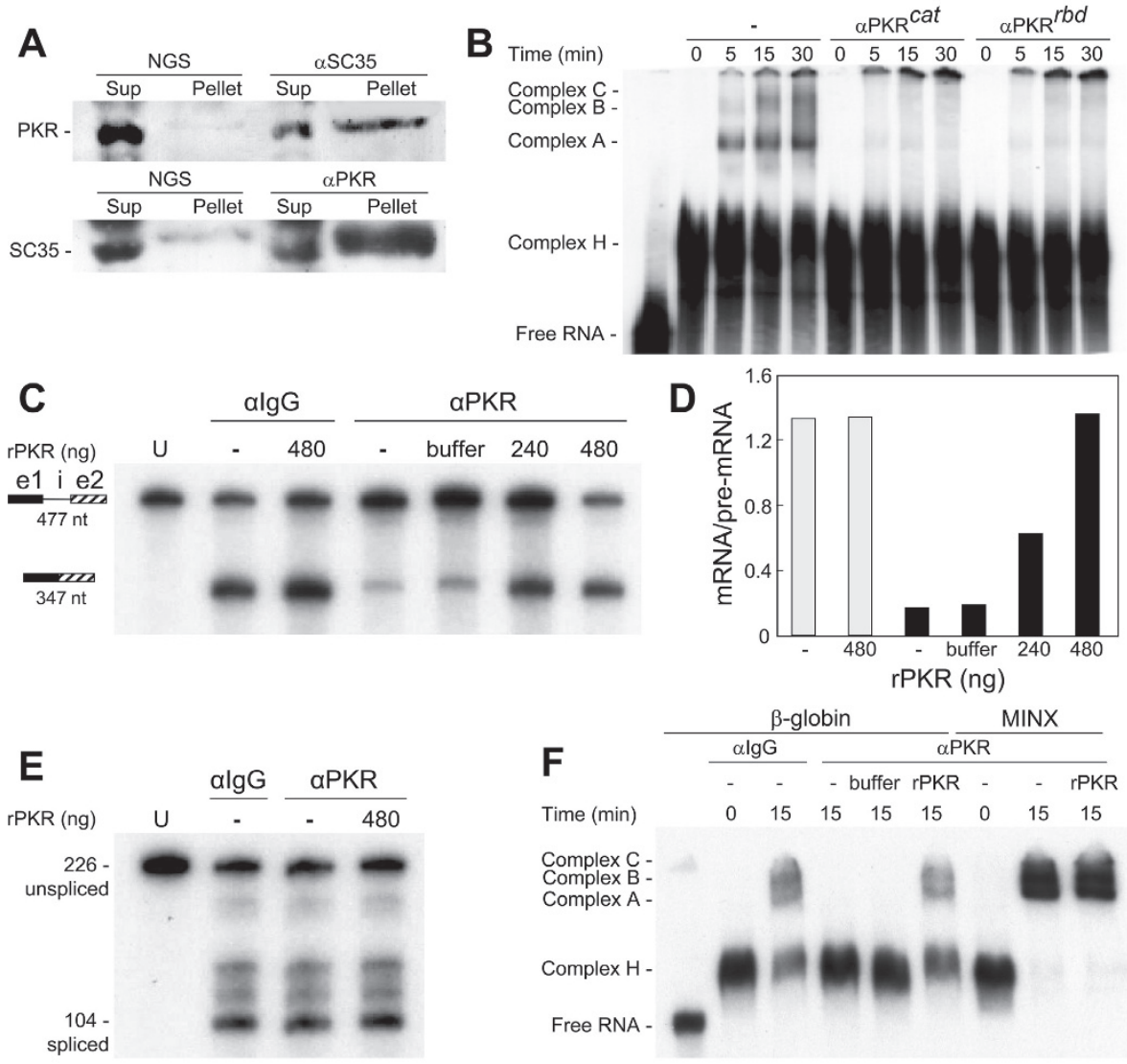

Figure $3 \mathrm{PKR}$ is in splicing complexes and required for splicing and spliceosome formation. (A) $\beta$-globin pre-mRNA template was incubated in HeLa cell nuclear extract for 30 min before immunoprecipitation with NGS, $\alpha$ SC35 or $\alpha$ PKR. Western blots of PKR (top) and SC35 (bottom) are shown for soluble (Sup) and precipitated fractions (Pellet). (B) Anti-PKR Abs inhibit spliceosome formation. Labeled $\beta$-globin pre-mRNA template was incubated in HeLa cell nuclear extract for the times shown. Where indicated, $\alpha \mathrm{PKR}^{\text {cat }}$ or $\alpha \mathrm{PKR}^{\mathrm{rbd}}$ was added 20 min before incubation. Ribonucleoprotein splicing complexes $\mathrm{A}, \mathrm{B}, \mathrm{C}$ and $\mathrm{H}$ were resolved by native PAGE. Left lane shows input unspliced RNA. (C-D) Recombinant PKR (rPKR) reconstitutes $\beta$-globin pre-mRNA splicing upon PKR depletion. (C) After adding $\mathrm{NaCl}$ to $500 \mathrm{mM}$, nuclear extract was incubated at $4{ }^{\circ} \mathrm{C}$ with $\alpha \lg$ or $\alpha$ PKR Ab for $18 \mathrm{~h}$; the immunoprecipitate was removed using protein A/G Sepharose beads. The depleted extract was centrifuged through Sephadex G-25 before in vitro splicing was performed for $2 \mathrm{~h}$, with rPKR or storage buffer (buffer) added as shown. (D) Plot of mRNA/pre-mRNA ratio in C; $\alpha$ lgG, grey bars; $\alpha$ PKR, black bars. (E) In parallel, splicing of MINX RNA was assayed as in C. U, input unspliced RNA. (F) Reconstitution of spliceosomes on $\beta$-globin pre-mRNA template with rPKR. Formation of spliceosomes was assayed as in B, using extract depleted of PKR as in $\mathbf{C}$. Where indicated, 480 ng of rPKR was added back. Three lanes on right show MINX RNA, assayed in parallel. 
Recombinant PKR (rPKR) reconstitutes $\beta$-globin mRNA splicing upon PKR depletion

Splicing of the $\beta$-globin pre-mRNA template was virtually eliminated when PKR was depleted by immunoprecipitation with anti-PKR Ab, whereas anti-IgG had no effect (Figure 3C). Splicing in PKR-depleted nuclear extract was restored in full by adding back rPKR (Figure 3C-3D). By contrast, splicing of MINX RNA was completely resistant to PKR depletion, showing specificity (Figure 3E). Likewise, formation of splicing complexes A-C on $\beta$-globin pre-mRNA template, but not on MINX RNA, was abolished by PKR depletion, and was restored by adding back rPKR (Figure 3F). Of note, to avoid co-immunoprecipitation of splicing factors with PKR, we performed the immunoprecipitation in the presence of $500 \mathrm{mM} \mathrm{NaCl}$ [25], and desalted the nuclear extract by gel filtration before the splicing reaction. Splicing and spliceosome formation likewise were restored in full by rPKR when the nuclear extract was desalted by dialysis (Supplementary information, Figure S1B-S1C). These reconstitution experiments validate the specificity of anti-PKR Ab that blocks splicing (Figures 2 and 3) and demonstrate directly that splicing of $\beta$-globin mRNA is PKR-dependent.

Addition of rPKR did not further stimulate splicing in $\alpha \mathrm{IgG}$-treated nuclear extract (Figure 3D), indicating that unlike the RNA-mediated activation of PKR, the level of this kinase, an abundant protein in the cell (Supplementary information, Figure S1A), does not limit $\beta$-globin mRNA splicing

eIF $2 \alpha$ phosphorylation is required for splicing of $\beta$-globin $m R N A$

PKR inhibits translation initiation by phosphorylating its substrate eIF $2 \alpha$. We considered the possibility that eIF $2 \alpha$ phosphorylation might play a role in $\beta$-globin mRNA splicing. First, we studied splicing of $\beta$-globin pre-mRNA template in nuclear extract in the presence of recombinant vaccinia virus $\mathrm{K} 3 \mathrm{~L}$ protein, which acts as a pseudosubstrate of PKR that binds the kinase and thus blocks its catalytic site [26, 27]. K3L effectively inhibited splicing of $\beta$-globin pre-mRNA template but not that of $M I N X$ pre-mRNA (Figure 4A).

Because K3L blocks autophosphorylation of PKR and phosphorylation of eIF $2 \alpha$ [26], we next examined the role of eIF $2 \alpha$ phosphorylation in $\beta$-globin mRNA splicing. Indeed, eIF $2 \alpha$ was phosphorylated during the splicing reaction (Figure 4B). The anti-phospho-eIF $2 \alpha$ $\mathrm{mAb}$, which did not recognize unphosphorylated eIF $2 \alpha$ (Figure 4B, zero time point), blocked splicing of $\beta$-globin pre-mRNA template but not that of $M I N X$ pre-mRNA (Figure 4B) and completely inhibited formation of spli- ceosomal complex A on $\beta$-globin pre-mRNA template, showing a need for phosphorylated eIF $2 \alpha$ in the early stages of spliceosome assembly (Figure 4C). By contrast, spliceosomal complex assembly on MINX RNA was not affected by this mAb (Supplementary information, Figure S2A), demonstrating the selective requirement for phospho-eIF2 in $\beta$-globin mRNA splicing. Consistently, addition of recombinant non-phosphorylatable mutant eIF2S51A strongly inhibited splicing of $\beta$-globin pre-mRNA template (Figure 4D-4E), whereas addition of $w t$ eIF2 $\alpha$ did not (Figure 4D). Splicing of MINX premRNA, by contrast, was unaffected by eIF $2 \alpha$ S51A (Figure $4 \mathrm{E}$ ). Whereas eIF2 $\alpha \mathrm{S} 51 \mathrm{~A}$ inhibited $\beta$-globin mRNA splicing, phosphomimetic mutant eIF $2 \alpha$ S51D did not (Figure 4F), reinforcing the need for phospho-eIF2 $\alpha$.

We next followed splicing of $\beta$-globin mRNA in cells. Expression of non-phosphorylatable mutant eIF $2 \alpha \mathrm{S} 51 \mathrm{~A}$ [13] strongly reduced the splicing efficiency of $\beta$-globin mRNA (Figure 4G and Supplementary information, Figure S2B), whereas expression of $w t$ human eIF $2 \alpha$ did not (Figure 4G). These results extend the in vitro splicing data and show that phosphorylation of eIF $2 \alpha$ is needed for efficient splicing of full-length $\beta$-globin mRNA in the cell. We conclude that eIF $2 \alpha$ plays an essential role in splicing of $\beta$-globin mRNA and must be phosphorylated on Ser51 for splicing to occur.

\section{The RNA activator of $P K R$ resides in $\beta$-globin exon 1}

The $\beta$-globin pre-mRNA splicing template activates PKR (Figure 1H), raising the question of where this property maps within the 477-nucleotide (nt) RNA molecule. Progressive truncation from the $3^{\prime}$ end showed that the ability to activate PKR was fully maintained in the 5 '-terminal 124-nt RNA fragment but lost almost completely in the 5'-terminal 118-nt fragment; removal of the first 4 nts from the $5^{\prime}$ end compromised PKR activation (Figure 5A). The RNA activator of PKR thus maps to the first 124 nts of $\beta$-globin pre-mRNA comprising the 50nt 5 '-UTR and the first $74 \mathrm{nts}$ of the ORF, and is made up solely of exon 1 sequence.

Probing of the 124-nt RNA element by spontaneous cleavage analysis [28] supports the structure shown in Figure 5B. rPKR induced increased cleavage or protection from cleavage at various positions in the RNA element (Figure 5B), indicating that large sections of the activator RNA interact directly with PKR or undergo conformational changes upon binding of the kinase.

Splicing efficiency is coupled to the ability of the RNA to activate PKR

Our results so far show that $\beta$-globin pre-mRNA splicing template potently activates PKR (Figure $1 \mathrm{H}$ ) through 
A
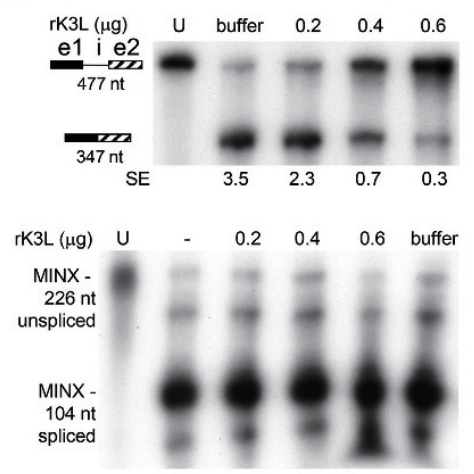

C

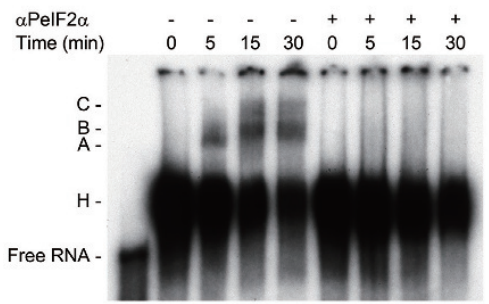

B

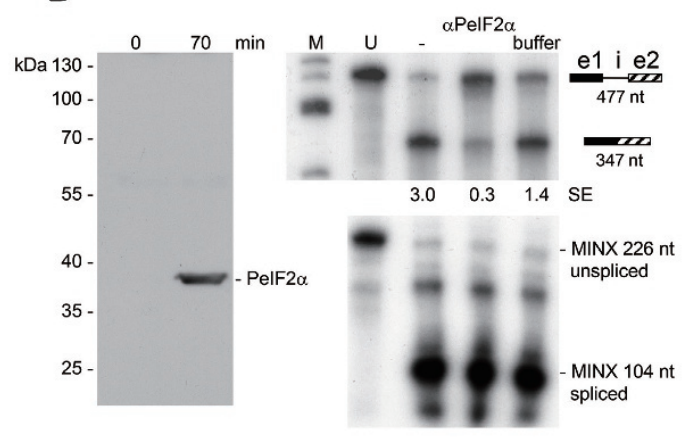

D

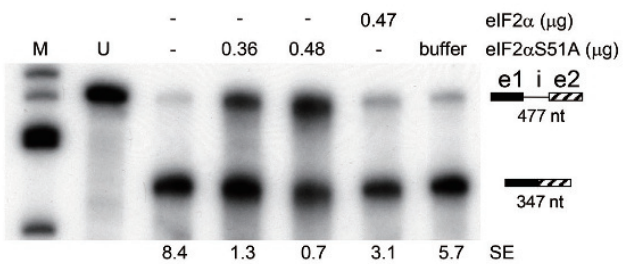

\section{$\mathbf{E}$}
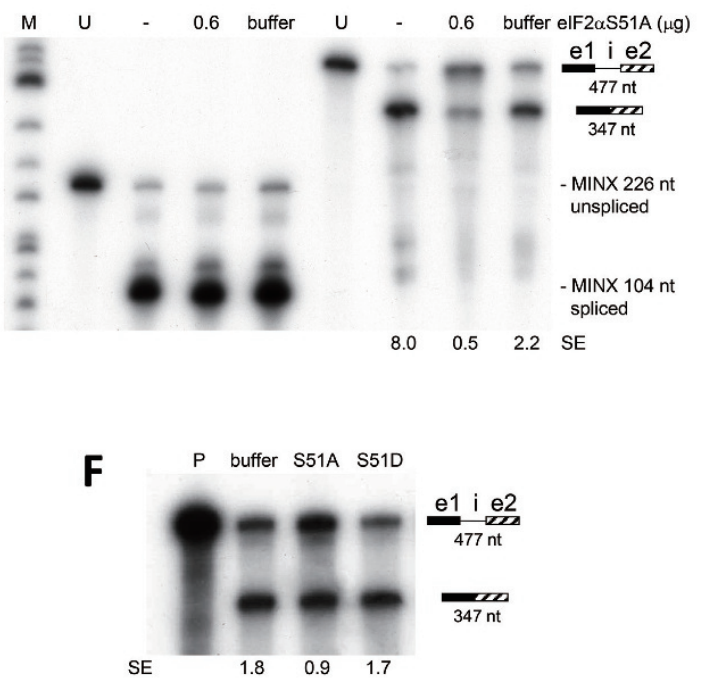

G

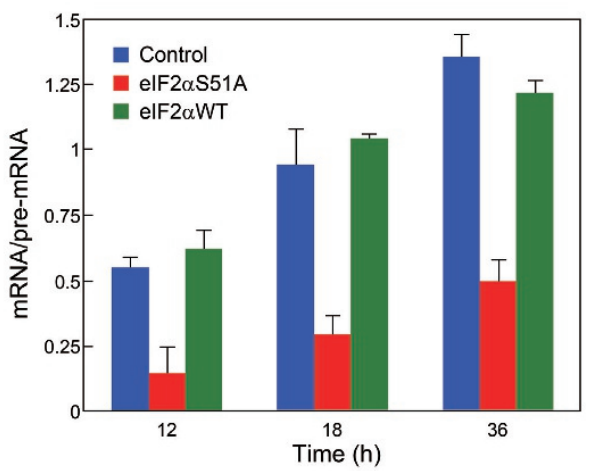

Figure $4 \beta$-Globin pre-mRNA splicing depends on elF2 $\alpha$ phosphorylation. (A) K3L inhibits splicing of $\beta$-globin mRNA. In vitro splicing was performed as in Figure 1F, using $\beta$-globin pre-mRNA template or MINX pre-mRNA. Before incubation, reaction mixtures were supplemented with recombinant $\mathrm{K} 3 \mathrm{~L}$ ( $\mathrm{rK} 3 \mathrm{~L}$ ) in the amounts shown. (B) Splicing of $\beta$-globin mRNA requires elF2 phosphorylation. Right, splicing was assayed as in $\mathbf{A}$, in the presence of anti-phospho-elF2 $\alpha$ mAb $(\alpha \operatorname{PelF} 2 \alpha ; 3 \mu \mathrm{g})$. Left, western blot of splicing reaction mixture with $\alpha$ PelF $2 \alpha$ shows mAb specificity and elF $2 \alpha$ phosphorylation at 70 min. (C) $\alpha$ PelF $2 \alpha$ inhibits early spliceosome formation. Labeled $\beta$-globin pre-mRNA template was incubated in HeLa cell nuclear extract for the times shown. Where indicated, $\alpha$ PelF2 $\alpha$ was added $30 \mathrm{~min}$ before addition of the RNA. Ribonucleoprotein complexes A, B, C and H were resolved by native PAGE. Left lane shows input unspliced RNA (Free RNA). (D-F) elF2 $\alpha$ S51A inhibits splicing of $\beta$-globin mRNA. Splicing was assayed as in B, in the presence of yeast elF2 $\alpha$ or elF2 $\alpha$ S51A (D, E) in the amounts shown, or of $0.5 \mu \mathrm{g}$ elF2 $\alpha$ S51A or elF2 $\alpha$ S51D (F). SE, splicing efficiency. (G) Expression of non-phosphorylatable mutant elF2 $\alpha$ S51A inhibits splicing of $\beta$-globin mRNA. HEK293T cells were co-transfected with equal amounts of $\beta$-globin gene vector and vector expressing human full-length elF2 $\alpha$ S51A or elF2 $\alpha \mathrm{WT}$, or empty vector (Control). At intervals after transfection, levels of spliced and unspliced $\beta$-globin transcripts were determined by qRT-PCR; splicing efficiency is expressed as the ratio of spliced RNA over unspliced RNA (means \pm SEM; $n=3$ ). 
its 5 '-terminal domain (Figure 5A) and that activation of PKR is needed for splicing of this RNA (Figures 2, 3B-3F and Supplementary information, Figure S1). We next asked whether during splicing, activation of PKR is accomplished by the splicing template itself. We mutated the short central helix $S 1$ consisting of $7 \mathrm{bp}$ within the 124-nt RNA element (Figure 5B) to yield $s 1 a$ and $s 1 b$ mutations. The $s 1 a$ and $s 1 b$ mutations disrupt 3 and 5 bp in helix $S 1$, respectively; this can explain why the $s 1 a$ mutation partially reduced the ability of the 477-nt $\beta$-globin pre-mRNA template to activate PKR, as revealed by assays using rabbit reticulocyte ribosomal fraction containing native PKR (Figure 5C) or rPKR (Figure 5D), whereas the $s l b$ mutation severely impaired PKR activation. Ability to activate PKR was restored, at least in part, in the double mutant $s 1 a b$ which retains 5 out of 7 bp in helix $S 1$ (Figure 5C-5D).

The failure of the $s 1 b$ pre-mRNA template to activate PKR (Figure 5C-5D) and to induce eIF2 $\alpha$ phosphorylation (Supplementary information, Figure S3A) was not due to a lack of the ability to bind PKR, because it competed as well as wt RNA for PKR binding in electrophoretic mobility shift analysis (Supplementary information, Figure S3B). Thus, binding of the $\beta$-globin RNA to PKR is insufficient for kinase activation, resembling the properties of the RNA activators of PKR in $\operatorname{IFN}-\gamma[13,14]$ and $T N F-\alpha$ (manuscript in submission) genes. The phenotype of these mutations was conserved in the 124-nt RNA element with respect to the ability to activate PKR and to induce eIF2 $\alpha$ phosphorylation (Figure $5 \mathrm{E}$ ). We conclude that helix $S 1$ shown in Figure 5B is maintained in the $\beta$-globin pre-mRNA splicing template

We next analyzed the effect of these mutations on splicing of the $\beta$-globin pre-mRNA template. sla and $s 1 b$ mutations severely impaired splicing efficiency and this was more pronounced for $s 1 b$. In contrast, the double mutation $s 1 a b$ restored splicing in part (Figure 5F-5G). Notably, the relative splicing efficiency for $w t, s 1 a, s 1 b$ and slab $\beta$-globin pre-mRNA templates correlated closely with their ability to activate rPKR at the lower RNA concentration, which was more sensitive to mutations (Figure 5D and 5G). Thus, splicing efficiency in HeLa cell nuclear extract containing all components needed for spliceosome formation reflects the ability of the RNA to activate PKR in an assay where the only macromolecules present are RNA and rPKR.

Reflecting their similar ability to activate native PKR (Figure $5 \mathrm{C}$ and $5 \mathrm{E}$ ), in an independent experiment, $w t$ and $s l a b$ mutant pre-mRNA templates were spliced with similar efficiency, which was inhibited by anti-phospho-eIF $2 \alpha$ mAb to a similar extent (Figure $5 \mathrm{H}$ ). Thus, compensatory mutation in slab RNA not only restores
PKR activation and splicing to $s 1 b$ mutant RNA but such splicing remains as dependent on eIF $2 \alpha$ phosphorylation as splicing of $w t$ RNA. Even though $s 1 b$ RNA is severely impaired in splicing, its low residual activity likewise requires phospho-eIF $2 \alpha$ (Figure $5 \mathrm{H}$ ).

Mutation of the PKR activator also affected $\beta$-globin mRNA splicing in the cell, where the $s 1 b$ mutation strongly impaired intron 1 excision (Figure 5I). The ratio of pre-mRNA/mRNA declined over time for the $w t$ gene as expected yet increased for the $s 1 b$ gene, attesting to a block in pre-mRNA processing. These results show that the splicing efficiency of the $\beta$-globin pre-mRNA template is regulated by its ability to activate PKR through the 124-nt exonic RNA element.

PKR activation and eIF2 $\alpha$ phosphorylation enable splicing of ${ }^{A} \gamma$-globin mRNA

Fetal $\gamma$-globin genes are related to the adult $\beta$-globin gene. Except for nt 25 in the $5^{\prime}$-UTR, ${ }^{G} \gamma$ - and ${ }^{A} \gamma$-globin gene sequences are identical through exon 2 [29]. We examined whether activation of PKR might also regulate excision of ${ }^{A} \gamma$-globin intron 1 . Indeed, as for $\beta$-globin (Figure 2E), PKR $\Delta 6$ strongly inhibited splicing of ${ }^{A} \gamma$-globin pre-mRNA template containing exon 1 , intron 1 and the first $172 \mathrm{nts}$ of exon 2 (Supplementary information, Figure S3C). ${ }^{A} \gamma$-Globin and $\beta$-globin pre-mRNA templates activated PKR comparably (Supplementary information, Figure S3D). ${ }^{A} \gamma$-Globin exon 1 RNA was sufficient to activate the kinase and induce eIF $2 \alpha$ phosphorylation (Supplementary information, Figure S3E). Splicing of ${ }^{A} \gamma$-globin and $\beta$-globin pre-mRNA templates was similarly inhibited by anti-phospho-eIF $2 \alpha \mathrm{mAb}$ (Supplementary information, Figure S3F). Thus, PKR activation and eIF2 phosphorylation also enable splicing of ${ }^{A} \gamma$-globin mRNA.

The ability of $\beta$-globin pre-mRNA to activate PKR is silenced upon splicing

During erythroid development, the cellular globin content rises from $<0.1 \%$ of the total protein amount in proerythroblasts to $95 \%$ in reticulocytes, reflecting a massive translation of globin mRNA [15]. Erythropoiesis would be compromised severely if mature $\beta$-globin mRNA were to activate PKR and thereby inhibit its own translation, in a manner resembling that for $I F N-\gamma$ mRNA [13]. In reticulocyte lysates, rabbit globin mRNA does not detectably activate PKR [30]. Because the activator of PKR in $\beta$-globin pre-mRNA splicing template is made up solely of exon sequence (Figure $5 \mathrm{~A}$ ), there is a need for a mechanism by which the ability to activate PKR is blocked in mature human $\beta$-globin mRNA. Indeed, whereas the 477 -nt $\beta$-globin pre-mRNA template strong- 

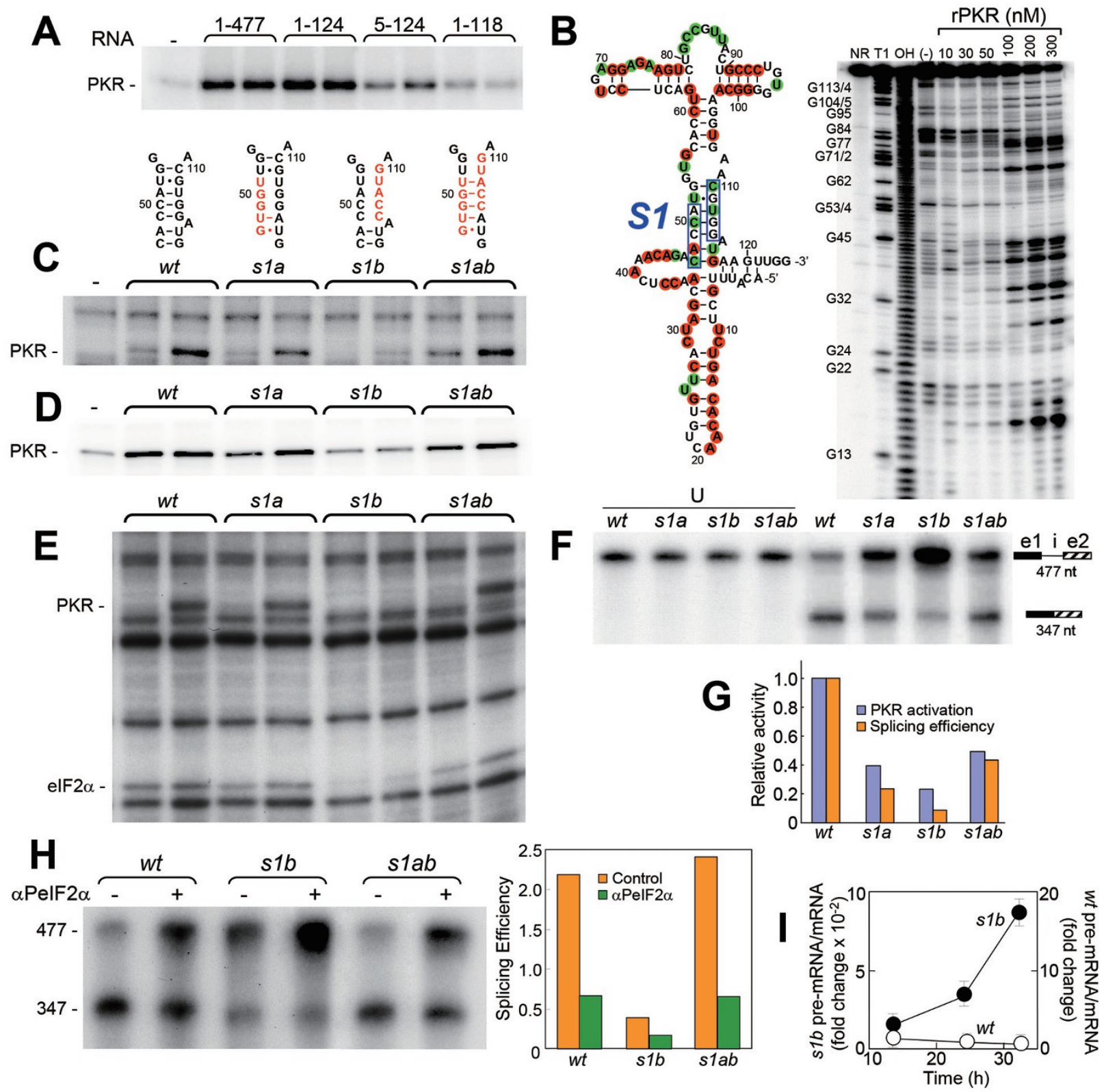

Figure 5 Splicing efficiency is coupled to activation of PKR by the activator in $\beta$-globin exon 1. (A) Activation of PKR by $\beta$-globin RNA. Phosphorylation of rPKR was assayed in the presence of $\left[\gamma-{ }^{32} \mathrm{P}\right] \mathrm{ATP}$, and 5 and $10 \mathrm{nM}$ intact $\beta$-globin pre-mRNA template (nts 1-477) or truncated RNAs (nts 1-124, 5-124 and 1-118). (B) In-line structure probing of the 5'-terminal 124 nts of the $\beta$-globin pre-mRNA template. Gel shows representative pattern of spontaneous cleavages in $5^{\prime}$ end-labeled RNA incubated alone (-) or with rPKR (nM) as shown. G (T1) and alkali $(\mathrm{OH})$ ladders serve as size markers; NR, input RNA. Structure on left is based on repeated in-line probing. Red and green colors denote nt showing enhanced and reduced cleavage, respectively, induced by rPKR. In helix S1, boxes denote nts mutated in s1a and s1b. (C-E) In s1a, positions 47-51 were mutated to GUGGU; in s1b, positions 110-114 were mutated to GUACC (red sequences in C). Activation of rabbit reticulocyte PKR (C, E) or rPKR (D) by wt or mutant forms of the 477-nt (C, D) or 124-nt (E) RNA was assayed; elF2 $\alpha$ phosphorylation is shown in $\mathbf{E}$. For activation of rabbit reticulocyte PKR, 1.2 and 2 nM RNA was used, and for rPKR, 5 and 10 nM RNA was used. (F, G) Splicing efficiency is coupled to the ability to activate PKR. (F) Splicing of wt and mutant forms of $\beta$-globin pre-mRNA template in HeLa cell nuclear extract was analyzed as in Figure 1F; left four lanes, input unspliced RNA (U). (G) Comparison of the ability to activate PKR at the lower RNA concentration in D and splicing efficiency (ratio of spliced RNA over pre-mRNA) in $\mathbf{F}$. (H) Splicing of $s 1 b$ pre-mRNA template is restored by compensatory mutation. In vitro splicing was assayed in the absence or presence of $\alpha$ PelF2 $\alpha(1 \mu \mathrm{g})$; splicing efficiency is plotted in the bar graph. (I) $\beta$-globin precursor RNA processing is coupled to the ability to activate PKR. HEK293T cells were transfected with wt- or $s 1 b$-mutant $\beta$-globin gene and excision of intron 1 was assayed by quantitative RT-PCR; ratio of unspliced over spliced RNA is plotted (means \pm SEM; $n=3$ ). 
ly activated PKR (Figure 6A, e-i-e), the spliced mRNA product consisting of exon 1 and the first $205 \mathrm{nts}$ of exon 2 activated PKR weakly (at high RNA concentration) or not at all (at low RNA concentration) (Figure 6A, e/e). Apparently, upon excision of intron 1, the RNA activator of PKR in $\beta$-globin pre-mRNA template is silenced.

To explore the silencing mechanism, we first truncated the second exon from the $3^{\prime}$ end. $\beta$-globin mRNA fragment containing exon 1 and the first 21 nts of exon 2 failed to activate PKR significantly; even truncation that left only $10 \mathrm{nts}$ of exon 2 fused to exon 1 sufficed to impair the ability to activate PKR (Figure 6A). This result suggests that when juxtaposed to exon 1, the first $10 \mathrm{nts}$ of exon 2 are able to silence the PKR activator in exon 1. The first $10 \mathrm{nts}$ of exon 2 sequence contains a $5^{\prime}-\mathrm{UG}-$ GUG-3' motif $(S 1 c)$ that in principle could anneal with the 3'-ACCAC-5' motif in S1a, forming 5 stable bp and displacing the corresponding $S 1 b$ motif (Figure 6B, modeled in Supplementary information, Figure S4A). To test this concept, we mutated the 5'-CACCA-3' motif in S1a to 5'-GUGGU-3' and/or changed the S1c motif to 5'-ACCAC-3' in the spliced e/e RNA. e/e RNA fragments with the resulting $s 1 a$ or $s 1 c$ mutation induced activation of PKR. The double mutation, ele slac, which restores base pairing between S1a and S1c, also restored silencing of PKR activation (Figure 6C).

The 477-nt $\beta$-globin pre-mRNA template with the sla mutation, which partially retains the base pairing within helix $S 1$, still possessed partial ability to activate PKR (Figure 5C). As the $s 1 a$ mutation abrogates base pairing with the $S 1 c$ silencer sequence, this could prevent the disruption of base pairing between $S 1 a$ and $S 1 b$ sequences after splicing (Figure 6B), and thus allow for residual PKR activation, as is indeed observed in Figure 6C.

We conclude that upon excision of intron 1, base pairing between $S 1 a$ and $S 1 b$ sequences within helix $S 1$, critical for activation of PKR by $\beta$-globin pre-mRNA template (Figure 5C-5E), is abrogated through displacement of $S 1 b$ by $S 1 c$ sequence located just downstream of the exon junction, within the first $10 \mathrm{nts}$ of exon 2. This results in silencing of the ability of the mature mRNA product to activate PKR. Silencing thus requires strand replacement within helix $S 1$ and as shown by ele slac, this process tolerates sequence inversion of the two complementary strands. Phylogenetic analysis shows that except for mouse $\beta$-globin major RNA, the potential for $S 1 a-S 1 b$ base pairing through the AUG codon is conserved, even in teleost fish (Supplementary information, Figure S4B).

An RNA activator of PKR resides in $\alpha$-globin exon 2

A hallmark of normal erythropoiesis is efficient syn- thesis of $\alpha$ - and $\beta$-globin in an equimolar ratio. We therefore investigated whether splicing of $\alpha$-globin mRNA is also regulated by activation of PKR and phosphorylation of eIF $2 \alpha$. In cells transfected with the human $\alpha 2$-globin gene, addition of 2-AP led to prompt accumulation of unspliced pre-mRNA (Figure 7A and Supplementary information, Figure S5). Splicing of the $\alpha$-globin premRNA template comprising exon 1 , intron 1 and all but 9 nts of exon 2 in HeLa cell nuclear extract was blocked by anti-phospho-PKR mAb (Figure 7B) and was at least as sensitive as splicing of $\beta$-globin pre-mRNA template to anti-phospho-eIF $2 \alpha$ mAb (Figure 7C). $\alpha$-Globin pre-mRNA template was as potent an activator of PKR as $\beta$-globin pre-mRNA template (Figure 7D). In contrast to $\beta$-globin, however, the $\alpha$-globin RNA activator of PKR mapped to exon 2 (Figure 7E). 3'-truncation of exon 2 RNA showed that a full PKR activation requires the first 179 nts of exon 2 (nts 250-428) and was largely lost upon removal of five additional nts from the $3^{\prime}$ end; 5 '-truncations defined a 123-nt core (nts 306-428) as the minimal activator (Figure 7F).

\section{A silencer of PKR activation resides in $\alpha$-globin exon 1}

Excision of intron 1 almost totally eliminated the ability of $\alpha$-globin RNA to activate PKR (Figure 7G). PKR activation was restored in part by truncation of the first $36 \mathrm{nts}$ of exon 1 and fully by deletion of the first $73 \mathrm{nts}$, placing the silencer of PKR activation within the 5'-proximal region of $\alpha$-globin exon 1 (Figure 7G). Thus, for both $\alpha$ - and $\beta$-globin genes, splicing of intron 1 depends on PKR activation and eIF2 $\alpha$ phosphorylation, but the respective positions of activator and silencer are reversed between the adjoining exons.

\section{Discussion}

Our finding is that splicing of globin mRNA requires not only activation of PKR by an intragenic RNA activator but also phosphorylation of the PKR substrate, eIF $2 \alpha$. There are similar requirements for the $T N F-\alpha$ gene encoding an inflammatory cytokine (manuscript in submission) suggesting the generality of our findings. Hemoglobin synthesis depends on optimal translation of globin mRNA in reticulocytes and globin reaches $95 \%$ of the total protein amount under conditions where no further transcription takes place [15]. Hence, local activation of PKR by globin mRNA, resulting in phosphorylation of eIF $2 \alpha$ and translational downregulation, would be detrimental. It is thus surprising that globin mRNA splicing depends strictly on activation of PKR as well as on phosphorylation of eIF $2 \alpha$, with the RNA activator of PKR not only being intrinsic to the globin pre-mRNA transcript 


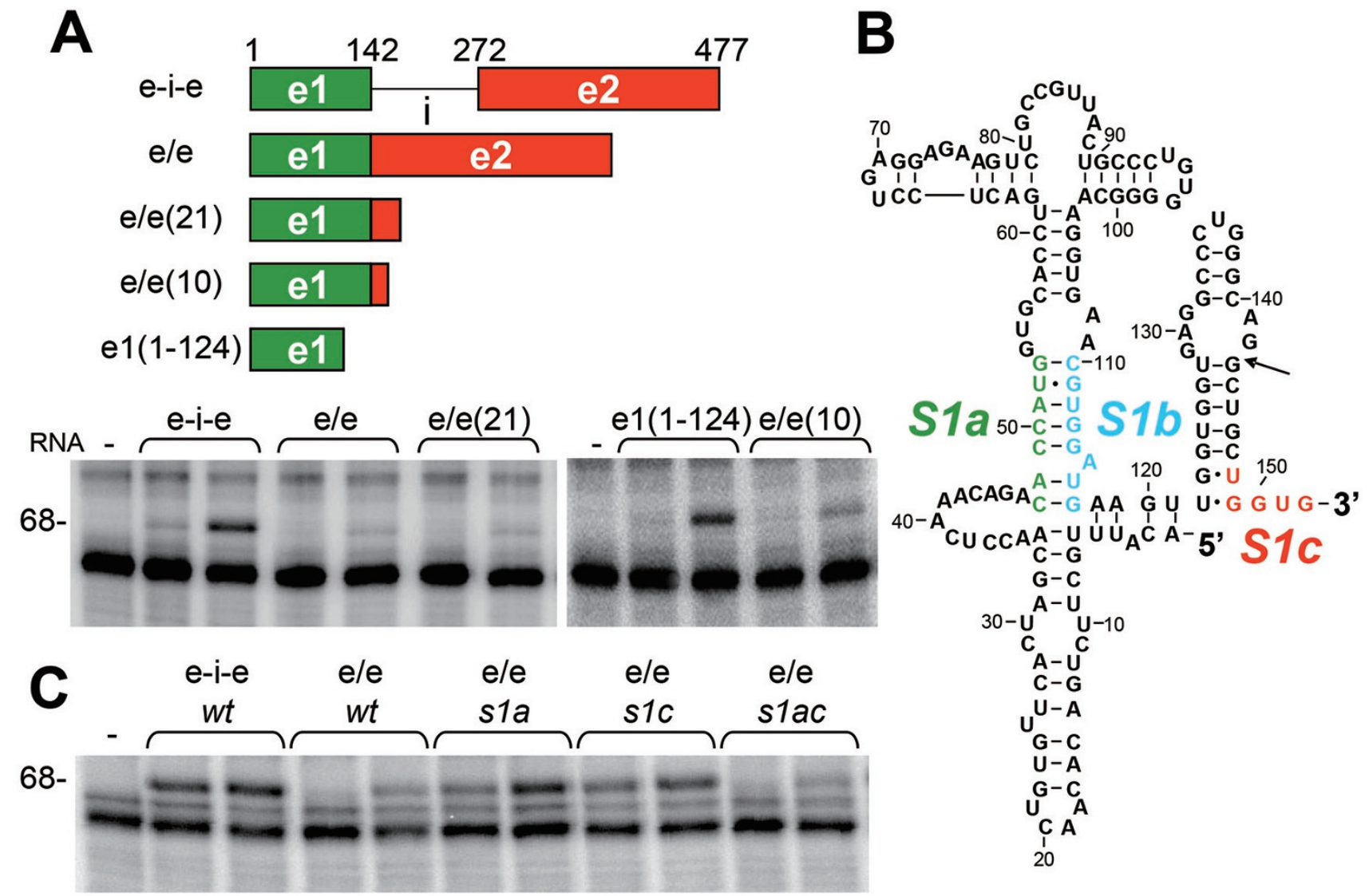

Figure 6 The ability to activate PKR is silenced upon splicing. (A) Excision of $\beta$-globin intron 1 causes silencing of the ability to activate PKR. Rabbit reticulocyte ribosome fraction was incubated with 1.2 and $2 \mathrm{nM}$ RNAs, including 477-nt $\beta$-globin pre-mRNA template (e-i-e), RNA comprised of 142-nt exon 1 joined to the first 205 (e/e), 21 (e/e(21)) or 10 nts (e/e(10)) of exon 2, or the 5'-terminal 124 nts of exon 1 (e1(1-124)) (see map). PKR activation was then determined by its autophosphorylation level (68 kDa band). (B) Schematic shows complementarity of S1b and S1c with S1a in e/e(10) RNA sequence; arrow indicates exon $1 / 2$ splice junction. (C) A mutation in $\beta$-globin exon 2 relieves silencing. In s1c, positions 148-152 were mutated to ACCAC. Activation of PKR by 1.2 and 2 nM pre-mRNA template (e-i-e) and wt or mutant forms of spliced RNA (e/e) was assayed using rabbit reticulocyte ribosome fraction.

but also located within an exon and therefore retained in the mature mRNA. The solution to this paradox is provided by a mechanism, demonstrated here, in which excision of the first intron induces an interaction between nucleotides in the adjacent exons, causing a structural rearrangement in the mRNA that silences the activator of PKR. Thus, whereas $\beta$-globin pre-mRNA potently activates PKR and induces phosphorylation of $\operatorname{eIF} 2 \alpha$, both required in the early stages of spliceosome assembly, the spliced mRNA no longer activates PKR. Use of RNA-mediated activation of PKR and eIF $2 \alpha$ phosphorylation to enable mRNA splicing reveals a dual function for this mechanism associated with the integrated stress response, yielding opposite outcomes in cytoplasm and nucleus.

On the basis of analysis in cells and in vitro, our data support a splicing control mechanism depicted in Figure 8. $\beta$-globin pre-mRNA exon 1 functions as a potent activator of PKR. Mutation of the activator profoundly affected splicing efficiency of $\beta$-globin pre-mRNA, in tight correlation with its ability to activate PKR. PKR was co-immunoprecipitated with SC35, showing that it associates with splicing complexes. PKR activation is a prerequisite for the first step in $\beta$-globin mRNA splicing, excision of intron 1 , which was blocked specifically by a dominant-negative mutant of PKR and by Abs against PKR and phospho-PKR, including an mAb that specifically targets phospho-Thr446, a pivotal residue in the kinase activity segment. Critically, both splicing and early spliceosome formation were abrogated by depletion of PKR and restored by adding back recombinant RNA-activatable holo-PKR. Should eIF2 kinases that are 
not activated by RNA [2] be capable of supporting $\beta$-globin mRNA splicing, these approaches would not have yielded an inhibition. Once PKR is activated, eIF2 $\alpha$ must be phosphorylated on Ser51 to allow formation of early-stage spliceosomal complex A. Splicing was inhibited by K3L, a viral eIF $2 \alpha$ pseudosubstrate of PKR, by anti-phospho-eIF $2 \alpha \mathrm{mAb}$ and by non-phosphorylatable mutant eIF $2 \alpha$ S51A, yet not by phosphomimetic eIF2 $\alpha$ S51D. As for $T N F-\alpha$ (manuscript in submission), expression of eIF $2 \alpha$ S5 $1 \mathrm{~A}$ blocked splicing of full-length $\beta$-globin mRNA in cells. The dependence of splicing on eIF $2 \alpha$ phosphorylation early during $\beta$-globin spliceosome assembly provides a mechanistic explanation for the need for PKR activation in splicing.

Upon excision of $\beta$-globin intron 1, a 5-nt exon 2 sequence $c$, located just downstream of the exon junction, displaces strand $b$ of short helix $a-b$ in the RNA activator of PKR in exon 1, which is critical for the ability of $\beta$-globin pre-mRNA to activate PKR (Figures 6 and 8). This displacement results in silencing of the ability of the exonic RNA element to activate PKR. Mutation of either strand $a$ or $c$ in this helix was sufficient to allow the spliced RNA product to activate PKR, whereas double mutation that restored base pairing resulted in restoration of silencing of the ability to activate PKR. In this manner, activation of PKR is eliminated once intron 1 has been excised. This RNA-mediated silencing mechanism ensures that the local activation of PKR serves solely to enable splicing.

$I F N-\gamma$ mRNA attenuates its own translation by locally activating PKR [13] through a structure comprised of the $5^{\prime}$-UTR and the first 26 codons, causing it to be disrupted by ribosomes during translation and requiring dynamic refolding to restore the activator [14]. Although the $\beta$-globin activator of PKR likewise spans the 5'-UTR and the first 25 codons of the ORF, $\beta$-globin mRNA does not activate PKR after splicing owing to the silencer mechanism.

$\alpha$ - and $\beta$-globin proteins are produced in an equimolar ratio but their genes differ in terms of chromosomal location, gene dosage, transcriptional control and mRNA stability $[31,32]$ as well as in the ability of their mRNAs to compete in translation $[33,34]$. We have shown that $\alpha$ - and $\beta$-globin genes share a regulatory strategy, i.e., dependence of mRNA splicing on activation of PKR and phosphorylation of eIF $2 \alpha$, but differ in the location of the elements that activate PKR and silence this property. Whereas the $\beta$-globin RNA activator of PKR is located in exon 1 , the $\alpha$-globin activator is composed solely of protein-encoding sequence in exon 2. Conversely, in $\beta$-globin mRNA the silencer of PKR activation is located in exon 2, whereas in $\alpha$-globin mRNA it resides in the 5 '-half of exon 1 . These distinct solutions demonstrate evolutionary flexibility in achieving the common aim of bringing mRNA splicing under the control of PKR activation. The first introns of $\alpha$ - and $\beta$-globin thus serve a novel function, to separate the PKR activator required for splicing from the silencer of PKR activation needed to enable translation.

Our experiments link eIF $2 \alpha$ phosphorylation to an early step in spliceosome assembly on globin mRNA, a complex and dynamic process in which the roles of multiple individual proteins remain to be delineated $[35,36]$. Whereas eIF $2 \alpha$ phosphorylation inhibits translation, we demonstrate a positive role for phosphorylation of eIF $2 \alpha$ on Ser51: it is necessary for splicing of globin mRNA. This requirement is shared with splicing enabled by the RNA activator of PKR in the TNF- $\alpha$ 3'-UTR, which is likewise abrogated by eIF2 $\alpha$ S51A expression (manuscript in submission). Splicing efficiency of $T N F-\beta$ pre-mRNA, which lacks a PKR activator, is strongly enhanced not only by inserting the $T N F-\alpha$ activator but also by merely increasing the level of phospho-eIF $2 \alpha$ globally in the cell by using an inhibitor of eIF $2 \alpha$ dephosphorylation, demonstrating that eIF $2 \alpha$ phosphorylation is both necessary and sufficient to achieve efficient splicing. Control of TNF mRNA splicing by eIF2 $\alpha$ phosphorylation operates in primary human immune cells, showing its physiological relevance (manuscript in submission).

Our results demonstrate a novel nuclear role for PKR and eIF $2 \alpha$ phosphorylation. A nuclear extract displays multiple important properties: the need for PKR in complex A formation on $\beta$-globin splicing template; inhibition of $\beta$-globin pre-mRNA splicing upon depletion of PKR and restoration of splicing by recombinant human PKR; restoration of complex A formation on a $\beta$-globin splicing template; phosphorylation of eIF $2 \alpha$ and the need for phospho-eIF $2 \alpha$ in complex A formation.

Differentiating human erythroleukemia cells do not express $\beta$-globin; very low levels of $\beta$-globin mRNA were detected, relative to $\alpha$-globin mRNA, in conditions inhibiting cell proliferation [37]. Even before induction of differentiation, K562 cells expressed fully spliced $\alpha$-globin mRNA, whereas pre-mRNA was not detectable (LSN, data not shown). We overcame the limitations of studying splicing of adult human globin mRNA in human cell lines by in vitro splicing assays and by genetic approaches, including gain-of-function mutations that provide mechanistic insight. Data from in vitro analysis of globin mRNA splicing were validated in transfected human and hamster cells.

Whereas human $T N F-\alpha$ and $I F N-\gamma$ genes contain potent intragenic activators of PKR, these elements display structural defects in the mouse (manuscript in submission, [14]). The mouse also differs significantly in terms 
A

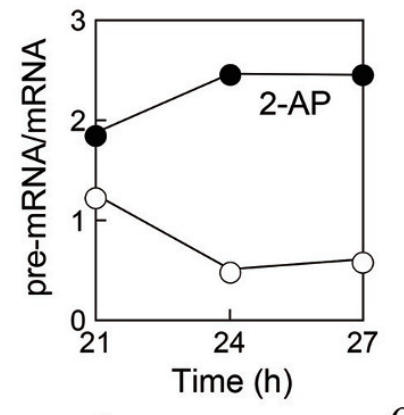

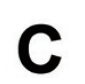

B

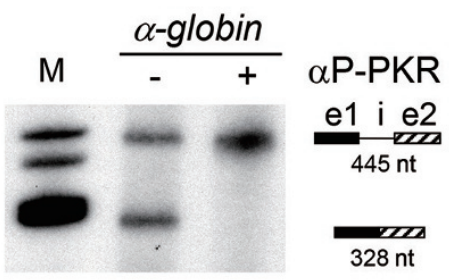

Time $(h)$

$\frac{\alpha-\text { globin }}{-+}$

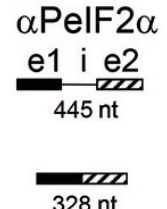

$328 \mathrm{nt}$

\section{$\mathrm{U}$}

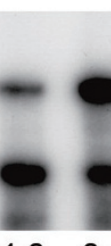

$\mathrm{U}$

\section{$\underline{\beta \text {-globin }}$}

\section{$\alpha$ PelF $2 \alpha$}

e1 i e2

$477 \mathrm{nt}$

$347 \mathrm{nt}$

SE

$\begin{array}{ll}1.6 & 0.4\end{array}$

$\begin{array}{ll}1.8 & 0.8\end{array}$
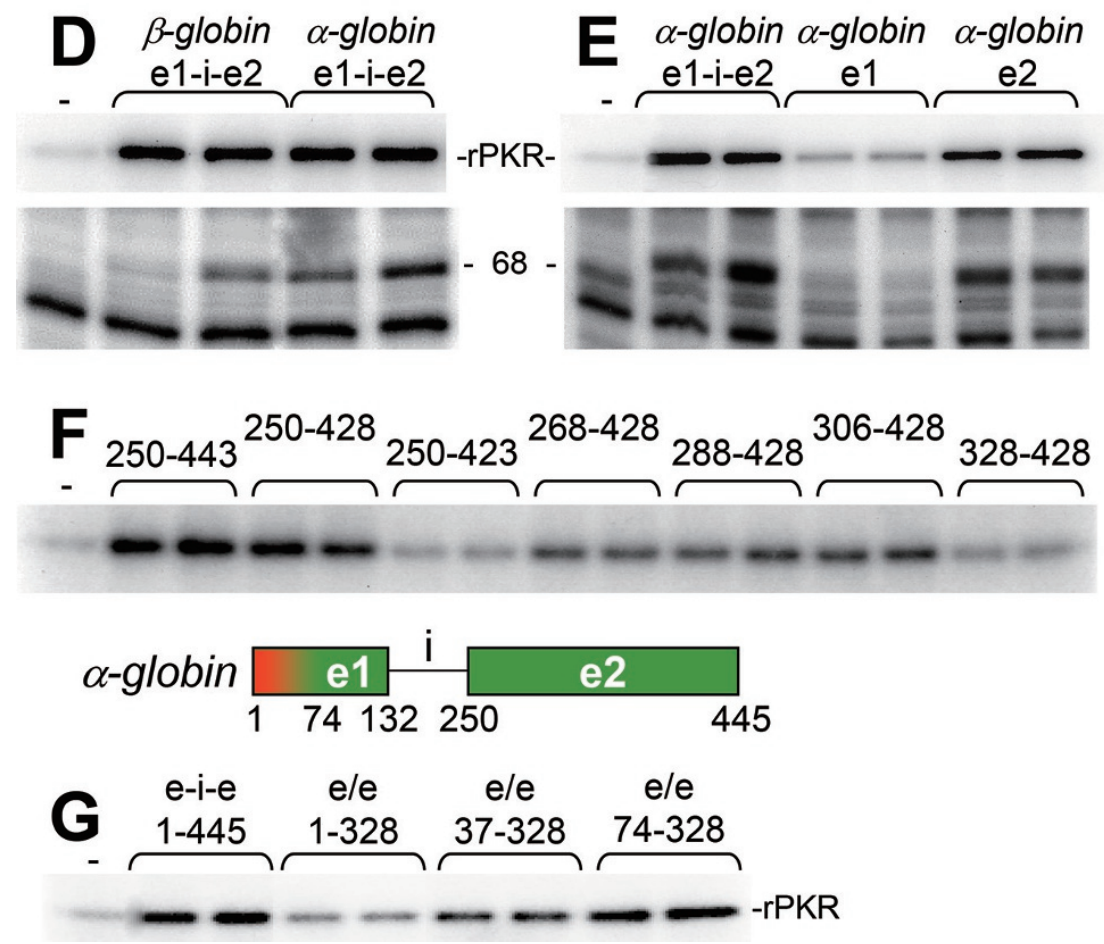

Figure 7 Excision of $\alpha 2$-globin intron 1 depends on PKR activation and elF2 $\alpha$ phosphorylation. (A) 2-AP inhibits splicing of $\alpha$-globin mRNA. HEK293T cells were transfected with the human $\alpha 2$-globin gene. 2-AP (15 mM) was added at $18 \mathrm{~h}$ after transfection. At times shown, expression of unspliced and spliced RNA was assayed by RNase protection analysis (Supplementary information, Figure S5). Pre-mRNA/mRNA ratio is plotted. (B, C) mAbs against phospho-PKR and phospho-elF2 $\alpha$ block splicing of $\alpha$-globin pre-mRNA template. Splicing of capped, ${ }^{32} \mathrm{P}$-labeled 445 -nt $\alpha$-globin pre-mRNA template in HeLa cell nuclear extract was analyzed as in Figure 2D, in the absence or presence of $1 \mu \mathrm{g} \alpha \mathrm{P}-\mathrm{PKR} \mathrm{mAb}(\mathrm{B})$ and for splicing of $\alpha-$ and $\beta$-globin pre-mRNA templates, in the absence or presence of $3 \mu \mathrm{g} \alpha \mathrm{PelF} 2 \alpha \mathrm{mAb}$ (C). SE, splicing efficiency. (D, E) The $\alpha$-globin RNA activator of PKR maps to exon 2. Activation of rPKR (top) or rabbit reticulocyte PKR (bottom) was assayed in the presence of 445 -nt $\alpha$-globin or 477-nt $\beta$-globin pre-mRNA template (e1-i-e2) (D) or in the presence of 445-nt pre-mRNA template (e1-i-e2), 132-nt exon 1 RNA (e1) or 196-nt exon 2 RNA (e2) of $\alpha$-globin (E). For activation of rabbit reticulocyte PKR, 1.2 and 2 nM RNA was used and for rPKR, 5 and 10 nM RNA was used. (F) Definition of the minimal $\alpha-g l o b i n ~ R N A$ activator of PKR. Activation of rPKR was analyzed in the presence of 5 and $10 \mathrm{nM} \alpha$-globin exon 2 RNA truncated to the positions shown (see map at bottom). (G) Excision of $\alpha$-globin intron 1 causes silencing of the ability to activate PKR. Activation of rPKR was analyzed in the presence of 5 and $10 \mathrm{nM} \alpha$-globin RNA as shown (e/e, 328-nt spliced form). The silencer maps to nts 1-74 in exon 1 , shown in red in the map. 


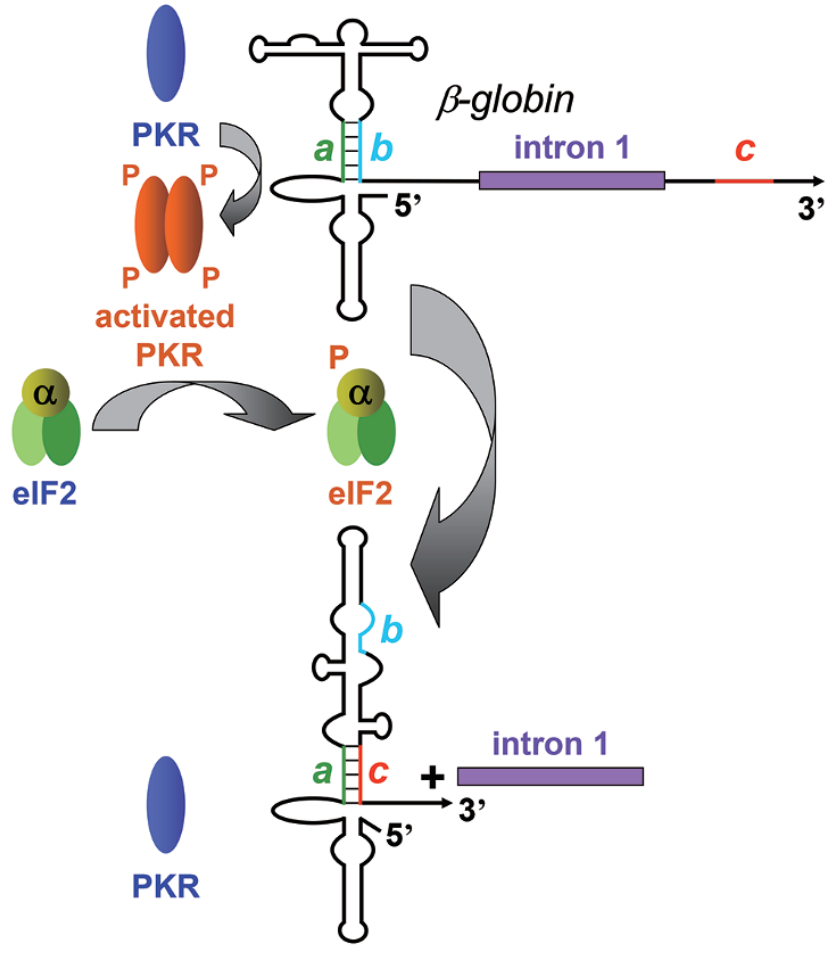

Figure 8 Model for regulation of $\beta$-globin mRNA splicing by an RNA activator of PKR in exon 1 and silencing of the PKR activator upon intron 1 excision. The activator of PKR in exon 1 relies on 5 bp $a-b$ pairing in helix $S 1$. Activation of PKR results in phosphorylation of elF2 $\alpha$, a prerequisite for excision of intron 1 (top). Excision of intron 1 juxtaposes exon 2 sequence $c$ and exon 1 sequence a, causing strand displacement in helix $S 1$ that silences the ability to activate PKR (bottom).

of $\beta$-globin gene organization, expressing major and minor species [38], impeding facile comparison with the human gene.

Synthesis of heme and globin is coordinated through a feedback loop wherein heme is needed to block activation of the eIF2 kinase HRI, thereby preventing attenuation of globin mRNA translation [39, 40]. Phosphorylation of eIF $2 \alpha$ by two distinct kinases, PKR and HRI, thus regulates separate steps in globin gene expression in nucleus and cytoplasm, i.e., mRNA splicing and translation, respectively. In the cytoplasm, eIF $2 \alpha$ is found in complex with eIF $2 \beta$ and $\gamma$ chains, forming holo-eIF2 active as translation factor [41]. Whether eIF2 $\beta$ and $\gamma$ subunits are involved in globin mRNA splicing is not yet known.

\section{Materials and Methods}

Gene transfection

Human embryonic kidney HEK293T cells were transiently transfected with $2 \mu \mathrm{g} \mathrm{pBS}$ vector carrying the $5 \mathrm{~kb} P$ st $\mathrm{I}-P s t \mathrm{I}$ fragment of genomic $\beta$-globin DNA including the upstream and downstream regulatory sequences. $\beta$-globin gene lacking intron 2 was constructed by replacing sequence downstream from the $P m / I$ site in exon 2 with cDNA sequence. $\mathrm{p} \beta \mathrm{G}(\mathrm{e} 1-\mathrm{i}-\mathrm{e} 2) \mathrm{GFP}$ and $\mathrm{p} \beta \mathrm{G}(\mathrm{e} 1-\mathrm{e} 2) \mathrm{GFP}$ contain $\beta$-globin exons 1 and 2 , with and without intron 1, respectively, under the tetracycline-inducible promoter, exon 2 being fused in-frame to the EGFP ORF at the BamHI site 18 bp upstream from the $3^{\prime}$ end of exon 2 . These two vectors were used to stably transfect BHK-21 cells together with pTet-tTAK (Gibco BRL) in a ratio of 1:10. After four passages in DMEM medium, transfected cells were induced with $12.5 \mathrm{pg} / \mathrm{ml}$ tetracycline; cells showing over $70 \%$ fluorescence were selected. Expression of PKR $\Delta 6$ was performed as described [13].

Splicing assay by RNase protection analysis

To generate $\beta$-globin intron 1 splicing probe (probe a), genomic DNA was digested with $N c o$ I and $N s p I$ and the filled-in fragment ligated into HincII-digested $\mathrm{pBS}$ vector. To generate $\beta$-globin intron 2 splicing probe (probe b), 5'-CGGAATTCTACCCTTGGACCCAGAG-3' and 5'-CCCAAGCTTCGATCCTGAGACTTCCAC-3' were used as PCR primers on genomic DNA; the EcoRI-HindIII fragment was excised from the product and inserted into pBS vector. Total RNA was isolated with TRIzol Reagent (Invitrogen) and subjected to RNase protection analysis with RNases A and T1 [12, 42]. Band intensity in autoradiograms was quantitated with a Fujifilm BAS 1800II Phosphoimager.

\section{Splicing assay by quantitative real-time PCR}

Total cellular RNA was harvested using TRIzol Reagent (Invitrogen) and cDNA synthesized from $1 \mu \mathrm{g}$ RNA using Verso RTPCR Kit (ABgene) in a 20- $\mu 1$ reaction volume. Quantitative real-time PCR was performed using $0.25 \mu \mathrm{g}$ cDNA, $300 \mathrm{nM}$ primers/ probe Double-Dye (Taqman style) mix and Absolute Blue QPCR Mix (ABgene). Primers and probes specific for spliced (primers: 5'-AAGGTGAACGTGGATGAAGTT-3', 5'-AGCATCAGGAGTGGACAGAT-3'; probe: 5'-CCTGGGCAGGCTGCTGGTGGTC-3') and unspliced (primers: 5'- TATCAAGGTTACAAGACAGGTTTAAG-3', 5'-GCCTAAGGGTGGGAAAATAGAC-3'; probe: 5'-CTCTTGGGTTTCTGATAGGCACTGACTCT-3') forms of $\beta$-globin RNA and normalizing human $\beta$-actin gene were from PrimerDesign. Reactions were performed for 40 cycles $\left(95^{\circ} \mathrm{C}\right.$ for $15 \mathrm{~s}, 60^{\circ} \mathrm{C}$ for $30 \mathrm{~s}$ and $72{ }^{\circ} \mathrm{C}$ for $15 \mathrm{~s}$ ) using a Rotor-Gene 6000 instrument (Corbett Life Science). The $\Delta \Delta \mathrm{Ct}$ method was used to evaluate mRNA-to-pre-mRNA ratio. Amplification efficiency of spliced and unspliced forms, determined by CT slope, was similar and at least $99 \%$.

\section{In vitro splicing}

HeLa cell nuclear extract (Promega) and capped, ${ }^{32} \mathrm{P}$-labeled 477-nt human $\beta$-globin precursor SP6 transcript generated from BamHI-cut DNA template $\left(0.17 \mathrm{pmol}, 1.25 \times 10^{5} \mathrm{cpm} / \mathrm{pmol}\right)$ or adenovirus MINX SP6 transcript generated from BamHI-cut DNA template [21] were incubated for $3 \mathrm{~h}$ at $30{ }^{\circ} \mathrm{C}$ in splicing buffer (reaction volume, $25 \mu \mathrm{l}$ ) following instructions of the manufacturer (Promega). When the effect of $\alpha$ P-PKR (Calbiochem) or $\alpha$ P-eIF2 $\alpha$ (Abcam) was studied, the reaction was preincubated with $\mathrm{Ab}$ for $15 \mathrm{~min}$ at $30^{\circ} \mathrm{C}$ and 15 min at $4{ }^{\circ} \mathrm{C}$ before RNA and RNasin were added; for $\alpha$ PKR (Cell Signaling), $\alpha$ PKR $^{\text {cat }}$, and $\alpha$ PKR $^{\text {rbd }}$ (Santa Cruz), preincubation was carried out for 15 min at $4{ }^{\circ} \mathrm{C}$. RNA was 
extracted, precipitated and analyzed in 4\% polyacrylamide/8 M urea gels. For analysis of spliceosome formation, 4- $\mu 1$ samples were collected at time intervals, incubated for $10 \mathrm{~min}$ with $50 \mu \mathrm{g}$ heparin at $4{ }^{\circ} \mathrm{C}$, made $10 \%$ glycerol and separated on $3.75 \%$ native polyacrylamide gels (polyacrylamide:bis, $80: 1 ; 50 \mathrm{mM}$ Tris-base, $50 \mathrm{mM}$ glycine, $\mathrm{pH} 8.8$ ). The $\alpha$-globin pre-mRNA template for in vitro splicing, generated from HincII-digested human $\alpha 2$-globin DNA, was a 445-nt SP6 transcript. The ${ }^{A} \gamma$-globin pre-mRNA template was a 439-nt T3 transcript. 5'-end labeled HinfI-digested $\varphi$ X174 single-stranded DNA (Fermentas) served as size marker, except in Figures $1 \mathrm{G}$ and 2A where boiled 100-bp DNA ladder (New England Biolabs) was used.

\section{Co-immunoprecipitation of PKR and SC35}

Antibodies were bound to protein A-Sepharose (GE Healthcare) by incubation for $2 \mathrm{~h}$ at $4{ }^{\circ} \mathrm{C}$. Immunoprecipitation from HeLa nuclear extract was performed by addition of $12 \mu \mathrm{g} \alpha \mathrm{PKR}, 26.4 \mu \mathrm{g}$ $\alpha \mathrm{SC} 35$ (Santa Cruz) or $60 \mu \mathrm{g}$ NGS followed by incubation for 5 $\mathrm{h}$ at $4{ }^{\circ} \mathrm{C}$. Complexes were washed five times with the buffer containing $50 \mathrm{mM}$ Tris- $\mathrm{HCl}$ (pH 7.4), 5 mM EDTA, $150 \mathrm{mM} \mathrm{NaCl}, 1$ $\mathrm{M} \mathrm{KCl}, 0.2 \%$ bovine serum albumin, and $0.5 \%$ Triton $\mathrm{X}-100$.

\section{Mutagenesis}

$\beta$-globin sla mutant was generated by replacing the AleI-AleI fragment in $w t$ 1-477 bp DNA with 5'-CTGTGTTCACTAGCAACCTCAAACAGAGTGGT-3' annealed to 5'-ACCACTCTGTTTGAGGTTGCTAGTGAACACAG-3'. $s 1 b$ was created by PCR using phosphorylated primers 5'-GAAGTACCATGAAGTTGGTGGTGAGG-3' and 5'-ACCTTGCCCCACAGGG-3' with the wt 1-477 bp DNA template and KOD polymerase (Novagen) to generate linear full-length plasmid DNA carrying blunt ends; the product was purified on a $1 \%$ agarose gel and self-ligated. Mutant e/e s $1 c$ was generated from $\beta$-globin cDNA under the SP6 promoter by PCR, using primers 5'-TGCACCACGTCTACCCTTGGACCCAGAGG-3' and 5'-GCCTGCCCAGGGCCTCA-3'. Truncations were created using restriction enzyme digestion, ligation to annealed complementary oligonucleotides, or PCR; primer sequences will be supplied on request. Truncation of $\alpha 2$-globin and $\gamma$-globin exon 1/intron 1/exon 2 DNA was done by PCR using phosphorylated DNA primers with KOD polymerase as above.

\section{In-line structure probing of $R N A$}

For in-line probing of RNA, we adapted a previously described protocol [28]. About $1 \mathrm{nM} \mathrm{5}{ }^{32} \mathrm{P}$-labeled RNA was incubated for $40 \mathrm{~h}$ at $25^{\circ} \mathrm{C}$ in the buffer containing $20 \mathrm{mM} \mathrm{MgCl} / 20 \mathrm{mM}$ Tris$\mathrm{HCl} \mathrm{pH} \mathrm{8.3,} 100 \mathrm{mM} \mathrm{KCl}, 1.5 \mathrm{mM}$ dithiothreitol and 6\% (v/v) glycerol in the absence or presence of rPKR. RNA cleavage products were resolved by $10 \%$ PAGE.

\section{Recombinant proteins}

PKR, PKR $\Delta 6$ and K3L were cloned into pHTT7K [43] and expressed in Escherichia coli Rosetta(DE3)pLysS (Invitrogen) as full-length N-terminally hexahistidine-tagged proteins. PKR was expressed in RNA-activatable form and was $>98 \%$ pure on SDS$12 \%$ PAGE [14]. K3L was recovered from inclusion bodies by solubilization in $6 \mathrm{M}$ urea buffer and loaded onto a Ni-column that was eluted stepwise with imidazole buffer containing $6 \mathrm{M}$ urea; next, urea concentration was reduced 10 -fold in six dialysis steps.
$\mathrm{K} 3 \mathrm{~L}$ was renatured by dialysis against $0.5 \mathrm{M}$ arginine, $20 \%$ glycerol, phosphate-buffered saline before arginine concentration was reduced five-fold in four dialysis steps; it was stored in the final buffer. Saccharomyces cerevisiae eIF $2 \alpha$, eIF $2 \alpha$ S51A and eIF $2 \alpha$ S51D were cloned into $\mathrm{pET} 15 \mathrm{~b}$ and expressed as C-terminally truncated hexahistidine-tagged $25 \mathrm{kDa}$ proteins (manuscript in submission).

\section{Activation of PKR}

Uncapped RNA transcripts were purified by Sephadex G-50 gel chromatography, washed with ethanol and eluted with water as described [44]. Rabbit reticulocyte ribosomal fraction was prepared and activation of PKR by RNA was assayed as described [45]. Activation of $100 \mathrm{ng}$ rPKR by RNA was determined as described [14]. Unless otherwise noted, RNA concentrations used were 1.2 and 2 $\mathrm{nM}$ for rabbit reticulocyte ribosome fraction and 5 and $10 \mathrm{nM}$ for rPKR.

\section{Immunodepletion and reconstitution of PKR}

For immunodepletion of PKR from HeLa nuclear extract, 200 $\mu 1$ of the extract was brought to $500 \mathrm{mM} \mathrm{NaCl}$ [25], first incubated with $12 \mu \mathrm{g}$ of $\alpha \operatorname{IgG}$ or $\alpha \mathrm{PKR} \mathrm{Ab}$ for $18 \mathrm{~h}$ at $4{ }^{\circ} \mathrm{C}$ with head-overtail rotation, and then incubated with washed protein A/G Sepharose beads for $2 \mathrm{~h}$ at $4{ }^{\circ} \mathrm{C}$ with head-over-tail rotation before the nuclear extract was separated from the beads. To remove $\mathrm{NaCl}$, the depleted nuclear extract was either centrifuged through Sephadex G-25 or desalted by overnight dialysis in buffer $(20 \mathrm{mM}$ Hepes $\mathrm{pH} 7.9,0.5 \mathrm{mM}$ dithiothreitol, $20 \%$ (v/v) glycerol, and $0.5 \mathrm{mM}$ phenylmethylsulfonyl fluoride) before in vitro splicing was performed for $2 \mathrm{~h}$ with or without rPKR or storage buffer.

\section{Acknowledgments}

We thank Blanka Shanitzki for assistance in quantitative real-time PCR. This work was supported by grants from the Israel Science Foundation.

\section{Author Contributions}

LI, FO, LSN and RK designed research; LI, FO, LSN, EE, SC$\mathrm{C}$, YB-A and YB performed research and analyzed data; RK, LI and LSN wrote the manuscript.

\section{Competing Financial Interests}

The authors declare no competing financial interests.

\section{References}

1 Nallagatla SR, Toroney R, Bevilacqua PC. Regulation of innate immunity through RNA structure and the protein kinase PKR. Curr Opin Struct Biol 2011; 21:119-127.

2 Sonenberg N, Hinnebusch AG. Regulation of translation initiation in eukaryotes: mechanisms and biological targets. Cell 2009; 136:731-745.

3 Harding HP, Zhang Y, Zeng $\mathrm{H}$, et al. An integrated stress response regulates amino acid metabolism and resistance to oxidative stress. Mol Cell 2003; 11:619-633.

4 Muaddi H, Majumder M, Peidis P, et al. Phosphorylation of eIF2 $\alpha$ at serine 51 is an important determinant of cell survival and adaptation to glucose deficiency. Mol Biol Cell 2010; 


\section{1:3220-3231.}

5 Tsaytler P, Harding HP, Ron D, Bertolotti A. Selective inhibition of a regulatory subunit of protein phosphatase 1 restores proteostasis. Science 2011; 332:91-94.

6 Kaempfer R. Identification and RNA-binding properties of an initiation factor capable of relieving translational inhibition induced by heme deprivation or double-stranded RNA. Biochem Biophys Res Commun 1974; 61:591-597.

7 Farrell PJ, Balkow K, Hunt T, Jackson RJ, Trachsel H. Phosphorylation of initiation factor eIF-2 and the control of reticulocyte protein synthesis. Cell 1977; 11:187-200.

8 Zhang F, Romano PR, Nagamura-Inoue T, et al. Binding of double-stranded RNA to protein kinase PKR is required for dimerization and promotes critical autophosphorylation events in the activation loop. J Biol Chem 2001; 276:2494624958.

9 Dey M, Cao C, Dar AC, et al. Mechanistic link between PKR dimerization, autophosphorylation, and eIF $2 \alpha$ substrate recognition. Cell 2005; 122:901-913.

10 Bevilacqua PC, Cech TR. Minor-groove recognition of double-stranded RNA by the double-stranded RNA-binding domain from the RNA-activated protein kinase PKR. Biochemistry 1996; 35:9983-9994.

11 Manche L, Green SR, Schmedt C, Mathews MB. Interactions between double-stranded RNA regulators and the protein kinase DAI. Mol Cell Biol 1992; 12:5238-5248.

12 Osman F, Jarrous N, Ben-Asouli Y, Kaempfer R. A cis-acting element in the 3 '-untranslated region of human TNF- $\alpha$ mRNA renders splicing dependent on the activation of protein kinase PKR. Genes Dev 1999; 13:3280-3293.

13 Ben-Asouli Y, Banai Y, Pel-Or Y, Shir A, Kaempfer R. Human interferon-gamma mRNA autoregulates its translation through a pseudoknot that activates the interferon-inducible protein kinase PKR. Cell 2002; 108:221-232.

14 Cohen-Chalamish S, Hasson A, Weinberg D, et al. Dynamic refolding of IFN- $\gamma$ mRNA enables it to function as PKR activator and translation template. Nat Chem Biol 2009; 5:896903.

15 Nienhuis AW, Benz EJ. Regulation of hemoglobin synthesis during the development of the red cell. N Engl J Med 1977; 297:1318-1328.

16 Samuel CE. Role of the RNA-dependent protein kinase in the regulated expression of genes in transfected cells. Pharmacol Ther 1992; 54:307-317.

17 Custódio N, Carvalho C, Condado I, et al. In vivo recruitment of exon junction complex proteins to transcription sites in mammalian cell nuclei. RNA 2004; 10:622-633.

18 Koromilas AE, Roy S, Barber GN, Katze MG, Sonenberg N. Malignant transformation by a mutant of the IFN-inducible dsRNA-dependent protein kinase. Science 1992; 257:16851689.

19 Krainer AR, Maniatis T, Ruskin B, Green MR. Normal and mutant human $\beta$-globin pre-mRNAs are faithfully and efficiently spliced in vitro. Cell 1984; 36:993-1005.

20 Mermoud JE, Cohen P, Lamond AI. Ser/Thr-specific protein phosphatases are required for both catalytic steps of pre-mRNA splicing. Nucleic Acids Res 1992; 20:5263-5269.

21 Hartmuth K, Urlaub H, Vornlocher HP, et al. Protein composition of human prespliceosomes isolated by a tobramycin affinity-selection method. Proc Natl Acad Sci USA 2002; 99:16719-16724.

$22 \mathrm{Fu} \mathrm{XD}$, Maniatis T. The $35-\mathrm{kDa}$ mammalian splicing factor SC35 mediates specific interactions between U1 and U2 small nuclear ribonucleoprotein particles at the $3^{\prime}$ splice site. Proc Natl Acad Sci USA 1992; 89:1725-1729.

23 Spector DL, Fu XD, Maniatis T. Associations between distinct pre-RNA splicing components and the cell nucleus. EMBO J 1991; 10:3467-3481.

24 Michaud S, Reed R. An ATP-independent complex commits pre-mRNA to the mammalian spliceosome assembly pathway. Genes Dev 1991; 5:2534-2546.

25 Makarova OV, Makarov EM, Lührmann R. The 65 and 110 $\mathrm{kDa}$ SR-related proteins of the U4/U6.U5 tri-snRNP are essential for the assembly of mature spliceosomes. EMBO J 2001; 20:2553-2563.

26 Carroll K, Elroy-Stein O, Moss B, Jagus R. Recombinant vaccinia virus $\mathrm{K} 3 \mathrm{~L}$ gene product prevents activation of double-stranded RNA-dependent, initiation factor $2 \alpha$-specific protein kinase. J Biol Chem 1993; 268:12837-12842.

27 Dar AC, Sichieri F. X-ray crystal structure and functional analysis of vaccinia virus $\mathrm{K} 3 \mathrm{~L}$ reveals molecular determinants for PKR subversion and substrate recognition. Mol Cell 2002; 10:295-305.

28 Soukup GA, Breaker RR. Relationship between internucleotide linkage geometry and the stability of RNA. 1999; RNA 5:1308-1325.

29 Slightom JL, Blechl AE, Smithies O. Human fetal ${ }^{\mathrm{G}} \gamma$ - and ${ }^{\mathrm{A}} \gamma$-globin genes: complete nucleotide sequences suggest that DNA can be exchanged between these duplicated genes. Cell 1980; 21:627-638.

30 Rosen H, Di Segni G, Kaempfer R. Translational control by messenger RNA competition for eukaryotic initiation factor 2. J Biol Chem 1982; 257:946-952.

31 Higgs DR, Garrick D, Anguita E, et al. Understanding $\alpha$-globin gene regulation: aiming to improve the management of thalassemia. Ann NY Acad Sci 2005; 1054:92-102.

32 Mahajan MC, Karmakar S, Weissman SM. Control of beta globin genes. $J$ Cell Biochem 2007; 102:801-810.

33 Lodish HF. Alpha and beta globin messenger ribonucleic acid. Different amounts and rates of initiation of translation. $J$ Biol Chem 1971; 246:7131-7138.

34 Di Segni G, Rosen H, Kaempfer R. Competition between $\alpha$ and $\beta$-globin messenger ribonucleic acids for eukaryotic initiation factor 2. Biochemistry 1979; 18:2847-2854.

35 Wahl MC, Will CL, Lührmann R. The spliceosome: design principles of a dynamic RNP machine. Cell 2009; 136:701718.

36 Hoskins AA, Moore MJ. The spliceosome: a flexible, reversible macromolecular machine. Trends Biochem Sci 2012; 37:179-188.

37 Shiraishi M, Yamamoto Y, Hirooka N, et al. A high concentration of triiodothyronine attenuates the stimulatory effect on hemin-induced erythroid differentiation of human erythroleukemia K562 cells. Endocr J 2015; 62:431-440.

38 Hoffmann FG, Opazo JC, Storz JF. New genes originated via multiple recombinational pathways in the beta-globin gene family of rodents. Mol Biol Evol 2008; 25:2589-2600.

39 Kaempfer R, Kaufman J. Translational control of hemoglobin 
synthesis by an initiation factor required for recycling of ribosomes and for their binding to messenger RNA. Proc Natl Acad Sci USA 1972; 69:3317-3321.

40 Chen JJ. Regulation of protein synthesis by the heme-regulated eIF2 $\alpha$ kinase: relevance to anemias. Blood 2007; 109:2693-2699.

41 Aitken CE, Lorsch JR. A mechanistic overview of translation initiation in eukaryotes. Nat Struct Mol Biol 2012; 19:568576.

42 Jarrous N, Osman F, Kaempfer R. 2-Aminopurine selectively inhibits splicing of tumor necrosis factor alpha mRNA. Mol
Cell Biol 1996; 16:2814-2822.

43 Guerrier-Takada C, Eder PS, Gopalan V, Altman S. Purification and characterization of Rpp25, an RNA-binding protein subunit of human ribonuclease P. RNA 2002; 8:290-295.

44 Circle DA, Neel OD, Robertson HD, Clarke PA, Mathews MB. Surprising specificity of PKR binding to delta agent genomic RNA. RNA 1997; 3:438-448.

45 Ben-Asouli Y, Banai Y, Hauser H, Kaempfer R. Recognition of 5'-terminal TAR structure in human immunodeficiency virus-1 mRNA by eukaryotic translation initiation factor 2 . Nucleic Acids Res 2000; 28:1011-1018.

(Supplementary information is linked to the online version of the paper on the Cell Research website.) 